\title{
Efficacy of Monotherapy with Biologics and JAK Inhibitors for the Treatment of Rheumatoid Arthritis: A Systematic Review
}

\author{
Paul Emery · Janet E. Pope - Klaus Kruger - Ralph Lippe • \\ Ryan DeMasi $\cdot$ Sadiq Lula $\cdot$ Blerina Kola
}

Received: May 14, 2018 / Published online: August 20, 2018

(C) The Author(s) 2018

\section{ABSTRACT}

Despite recommendations suggesting that biological and targeted synthetic disease-modifying antirheumatic drugs (b/tsDMARDs) should be used in combination with methotrexate in the treatment of rheumatoid arthritis (RA), up to one-third of patients with RA are treated with monotherapy. The objective of the systematic literature review reported here was to evaluate the clinical evidence regarding the efficacy of $\mathrm{b} / \mathrm{tsDMARDs}$ as monotherapy in the treatment

Enhanced digital features To view enhanced digital features for this article go to https://doi.org/10.6084/ m9.figshare.6724601.

Electronic supplementary material The online version of this article (https://doi.org/10.1007/s12325018-0757-2) contains supplementary material, which is available to authorized users.

P. Emery $(\bowtie)$

Leeds Musculoskeletal Biomedical Research Unit, LTHT and Leeds Institute of Rheumatic and Musculoskeletal Medicine, University of Leeds, Leeds, UK

e-mail: p.emery@leeds.ac.uk

J. E. Pope

University of Western Ontario, London, ON,

Canada

K. Kruger

Faculty of Medicine of the University of Munich, Munich, Germany of RA. MEDLINE ${ }^{\circledR}$, Embase $^{\circledR}$, and the Cochrane Central Trials Register (to April 11, 2017) and the American College of Rheumatology and European League Against Rheumatism conference proceedings (2010-2016) were searched for randomized controlled trials evaluating the efficacy of b/tsDMARDs as monotherapy for RA in adults. Forty-four monotherapy studies of abatacept, adalimumab, baricitinib, certolizumab pegol, etanercept, sarilumab, sirukumab, tocilizumab, and tofacitinib reported in 71 publications were identified. Tocilizumab had the most studies (14), followed by etanercept (10) and adalimumab (9). These b/tsDMARDs were consistently shown to be efficacious treatments, regardless of whether patients were intolerant of or had never used conventional synthetic (cs) DMARDs. However, better treatment outcomes were usually achieved with combination therapy, and this

\author{
R. Lippe \\ Pfizer, Berlin, Germany \\ R. DeMasi \\ Pfizer, Collegeville, PA, USA \\ S. Lula \\ Envision Pharma Group, London, UK \\ B. Kola \\ Pfizer, Tadworth, Surrey, UK
}


was observed for all b/tsDMARDs assessed by this review. Only a few studies provided a headto-head comparison between b/tsDMARD treatments or between b/tsDMARD monotherapy and combination therapy, and as many were initial RA treatments they were not generalizable to usual care. In conclusion, evidence from randomized trials suggests that the $\mathrm{b} / \mathrm{tsDMARDs}$ studied are effective as monotherapy. In general, some patient responses seem better with combination therapy and the durability of monotherapy is less than combination therapy. There is, however, a need for longer-term head-to-head trials to establish positioning of these interventions in the treatment algorithm for RA.

Funding: Pfizer.

Plain Language Summary: Plain language summary available on the journal website.

Keywords: Biological disease-modifying antirheumatic drugs; Monotherapy; Rheumatoid arthritis; Targeted synthetic disease-modifying antirheumatic drugs

\section{PLAIN LANGUAGE SUMMARY}

Rheumatoid arthritis is a chronic, long-term disease. Medication is often required to control symptoms including pain and swollen joints. Many patients take a class of treatment called disease-modifying antirheumatic drugs (DMARDs). There are different types of DMARD, synthetic and biologic. Current treatment guidelines recommend combining drugs such as methotrexate (a conventional synthetic DMARD) with other drugs such as etanercept (a biologic DMARD) or tofacitinib (a targeted synthetic DMARD). As many as one-third of patients with rheumatoid arthritis are treated with bDMARDs or tsDMARDs alone. This type of treatment is called monotherapy. The aim of this review was to investigate which $\mathrm{b} / \mathrm{tsDMARDs}$ are best used as monotherapy in the treatment of rheumatoid arthritis. Fortyfour monotherapy studies of nine different DMARDs were identified in a literature search.

These b/tsDMARDs were shown to be effective treatments, even in patients who were intolerant of or had never used csDMARDs.
However, better treatment outcomes were usually achieved with combination therapy. This was observed for all b/tsDMARDs assessed. Further studies are needed to show which treatments will be effective as monotherapy when used early in treating rheumatoid arthritis.

\section{INTRODUCTION}

Effective treatment of rheumatoid arthritis (RA) requires the use of disease-modifying antirheumatic drugs (DMARDs). Traditional synthetic compounds such as methotrexate (MTX), sulfasalazine, and leflunomide are classified as conventional synthetic DMARDs (csDMARDs). Other synthetic compounds such as the Janus kinase (JAK) inhibitors tofacitinib (TOFA) and baricitinib (BARI), specifically developed to target the JAKs, are classified as targeted synthetic DMARDS (tsDMARDs). Biologic DMARDS (bDMARDs) are recombinant biologic molecules that recognize cell surface receptors or extracellular molecules with high specificity [1]. The bDMARDs approved by the European Medicines Agency (EMA) and/or United States Food and Drug Administration (FDA) for use as monotherapy in the treatment of RA include the tumor necrosis factor (TNF) inhibitors adalimumab (ADA), certolizumab pegol (CZP), and etanercept (ETN), the T cell co-stimulation inhibitor abatacept (ABA), the interleukin (IL)-6 receptor (IL-6R)-blocking monoclonal antibodies (mAbs) sarilumab (SRL) and tocilizumab (TCZ), and the IL-1R-binding mAb anakinra (ANK). TOFA and BARI are also approved by the EMA and/or FDA for use as monotherapy in the treatment of RA $[2,3]$. The IL-6-binding $\mathrm{mAb}$ sirukumab (SRK) was submitted to the FDA for approval as a treatment for RA, but this was declined [4]. Infliximab and rituximab are not approved as monotherapy in RA.

Current European League Against Rheumatism (EULAR) recommendations for the treatment of RA support the use of MTX plus shortterm glucocorticoids (GC) as a first-line treatment, with the aim of a greater than 50\% improvement within 3 months and clinical remission within 6 months. If this fails, stratification based on disease prognosis is 
recommended. If there are no unfavorable prognostic markers (autoantibodies, high disease activity, early erosions, failure of two csDMARDs), patients should switch to or add another csDMARD. If unfavorable prognostic markers are present, a bDMARD or JAK inhibitor should be added to the csDMARD. If this also fails, switching to another bDMARD or tsDMARD is recommended [5].

Despite EULAR recommendations suggesting that bDMARDs should be used in combination with MTX, it has been estimated that from just under one-quarter $[6,7]$ to approximately onethird [8-12] of patients prescribed a b/tsDMARD take it as monotherapy, without concomitant csDMARD therapy. Patients receiving bDMARDs as monotherapy generally fall into one of three groups-those who never begin treatment with a csDMARD such as MTX, as treatment is either contraindicated or declined (csDMARD-naïve), those who initiate MTX but subsequently discontinue [csDMARD unresponsive or intolerant (csDMARD-U/I) or who do not adhere to their treatment] [10], and those who are in sustained remission and taper off csDMARD treatment. In the Danish study of patients on monotherapy, $70 \%$ of patients were on bDMARD monotherapy from biologic therapy initiation and 30\% were on bDMARD monotherapy after stopping treatment with concomitant csDMARD [6]. For both groups of patients, and their health care providers, knowing the efficacy of monotherapy versus combination therapy is of vital importance. Three recent systematic reviews have compared the efficacy of bDMARD monotherapy and tsDMARD monotherapy with MTX combination therapy in RA patients with an inadequate response to csDMARDs [13-15]. However, these reviews covered a limited number of randomized controlled trials (RCTs) and did not cover newer treatments such as BARI, SRL, and SRK. The relative benefit of one drug over another is also not fully known.

The objective of this systematic literature review (SLR) was to evaluate the clinical evidence regarding the efficacy of $b / t s D M A R D$ monotherapy in the treatment of RA, in order to help clinicians make the best treatment choices for their patients.

\section{METHODS}

\section{Search Methodology}

A comprehensive electronic search strategy of databases including MEDLINE, Embase, and the Cochrane database, executed on April 11, 2017, identified RCTs relevant to the study objectives. Controlled vocabulary and free-text terms were used and search results were filtered using the study designs of interest. In addition, a manual search of the American College of Rheumatology (ACR) and EULAR conference proceedings from 2010 to 2016 was undertaken to obtain recent studies not yet available as full-text articles. The full list of databases searched and the search strategies are listed in the Supplementary Materials, Tables 1-4.

This SLR was conducted using a standardized, thorough, and transparent approach, following Cochrane dual-reviewer methodology. The SLR protocol followed the Preferred Reporting Items for Systematic Reviews and Meta-Analyses protocol guidelines. All processes and methodologies used to conduct this SLR are summarized below and described fully in the Supplementary Materials.

\section{Study Selection and Data Extraction}

Studies were selected via a two-level screening process. At Level I, the titles and abstracts of publications identified in the literature searches were screened by one reviewer for eligibility according to the prespecified criteria described below. Any study not meeting all criteria was excluded. A second reviewer performed a quality check of a randomly selected $10 \%$ of all screened studies. The full text of publications that met eligibility criteria at Level I were retrieved for Level II screening. Any study found to be ineligible at Level II was excluded and the reason documented. An independent reviewer reviewed all publications eligible for inclusion and a randomly selected $20 \%$ of the publications excluded at Level II. Any discrepancies were resolved by a consensus among reviewers. 
RCTs were eligible for inclusion, with nonrandomized trials and observational studies, case reports, case series, and case studies being excluded. Previously published systematic/literature reviews, letters, commentaries, and editorials were also excluded, but were handsearched for relevant studies that could be included in the current SLR. Studies were included if the participants were adults ( $\geq 18$ years) diagnosed with RA according to a standardized diagnostic classification system (ACR 1987 or EULAR/ACR 2010 criteria). Studies were included if the bDMARDs or tsDMARDs listed in Table 1 were evaluated as monotherapy in the treatment of RA. For most treatments, only studies employing these drugs in dosage, form, and frequency of administration as recommended by health authorities [such as National Institute for Health and Care Excellence (NICE)], evidence-based clinical practice guidelines (ACR, EULAR, British Society for
Rheumatology), or consensus statements from expert panels, were included. Studies evaluating treatments approved or submitted for approval from 2012 onwards (BARI, SRL, SRK, TOFA) were not restricted to recommended dosing regimens. Study information including efficacy outcomes, details of study design, treatment data, and patients' baseline demographic and clinical characteristics were extracted from each study that met eligibility criteria.

\section{Risk of Bias Assessment}

The quality of RCTs was assessed using the recommendations from the NICE single technology appraisal manufacturer's template. RCTs were scored using the Jadad scoring system [16]. The quality of abstracts from conference proceedings was assessed using a modified Downs and Black instrument [17].

Table 1 List of included interventions and EMA/FDA recommended dosing intervals Sources: EMA [2], FDA [3]

\begin{tabular}{|c|c|c|c|}
\hline $\begin{array}{l}\text { Generic } \\
\text { name }\end{array}$ & Abbreviation & Alternative names & $\begin{array}{l}\text { Recommended label dose for RA } \\
\text { (FDA unless otherwise stated) }\end{array}$ \\
\hline Abatacept & $\mathrm{ABA}$ & $\begin{array}{l}\text { Orencia }^{\circledR}, \text { bms-188667, } \\
\text { CTLA4 ig }\end{array}$ & $\begin{array}{l}\text { Sc } 125 \mathrm{mg} \text { at week } 0 \text {, then every week (with or without an iv } \\
\text { loading dose) }\end{array}$ \\
\hline Adalimumab & $\mathrm{ADA}$ & Humira $^{\circledR}$ & $\begin{array}{l}\text { Sc } 40 \mathrm{mg} \text { every other week ( } 40 \mathrm{mg} \text { every week may be } \\
\text { considered) }\end{array}$ \\
\hline Anakinra & ANK & Kineret $^{\circledR}$ & Sc 100 mg per day \\
\hline Baricitinib & BARI & Olumiant $^{\circledR}$ & EMA: $4 \mathrm{mg}$ once daily \\
\hline $\begin{array}{l}\text { Certolizumab } \\
\text { pegol }\end{array}$ & CZP & $\begin{array}{l}\text { Cimzia }^{\circledR}, \text { CDP } 870, \\
\text { PHA738144 }\end{array}$ & $\begin{array}{l}\text { Sc } 400 \mathrm{mg} \text { at weeks } 2 \text { and 4, then } 200 \mathrm{mg} \text { every other week } \\
\text { (400 mg every } 4 \text { weeks may be considered) }\end{array}$ \\
\hline Etanercept & ETN & Enbrel $^{\circledR}$ & Sc $25 \mathrm{mg}$ twice weekly or $50 \mathrm{mg}$ weekly \\
\hline Sarilumab & SRL & Kevzara $^{\circledR}$ & Sc $200 \mathrm{mg}$ once every 2 weeks \\
\hline Sirukumab $^{\mathrm{a}}$ & SRK & $\mathrm{N} / \mathrm{A}$ & $\mathrm{N} / \mathrm{A}$ \\
\hline Tocilizumab & TCZ & $\begin{array}{c}\text { Actemra }^{\circledR}, \text { Atlizumab }^{\circledR}, \\
\text { R1569, Roactemra }\end{array}$ & $\begin{array}{l}\text { Iv } 4 \mathrm{mg} / \mathrm{kg} \text { at week } 0 \text {, then } 8 \mathrm{mg} / \mathrm{kg} \text { every } 4 \text { weeks or sc } \\
162 \mathrm{mg} \text { every other week, then every week }\end{array}$ \\
\hline Tofacitinib & TOFA & $\begin{array}{l}\text { CP690550, Jakvinus }{ }^{\circledR} \\
\text { tasocitinib, Xeljanz }^{\circledR}\end{array}$ & Oral $5 \mathrm{mg}$ twice daily \\
\hline
\end{tabular}

EMA European Medicines Agency, FD $A$ United States Food and Drug Administration, iv intravenous, $N / A$ not applicable, $R A$ rheumatoid arthritis, $s c$ subcutaneous

a Since the literature search for this systematic literature review was completed, the application for FDA approval of sirukumab to treat RA has been rejected and the product has been discontinued [4] 


\section{Compliance with Ethics Guidelines}

This article is based on previously conducted studies and does not contain any studies with human participants or animals performed by any of the authors.

\section{RESULTS}

\section{Literature Search Results}

The electronic literature search yielded 18,949 articles, with some overlap between the MEDLINE $^{\circledR} /$ Medline in process, Embase ${ }^{\circledR}$, and Cochrane Library databases. After removing duplicate articles indexed on MEDLINE, Embase, and the Cochrane Library, there were 14,991 unique publications. A manual review of reference lists of review articles, conference proceedings, and recommendations from experts within the field identified an additional 63 publications. The screening process identified 44 studies reported in 71 publications and is illustrated in Fig. 1. Details of the studies included in this review are presented in Table 2. The majority of the references were of excellent or good quality (Supplementary Tables 5 and 6). No publications for ANK met the inclusion criteria for this systematic review. Publications for SRK were included in this review as the application for FDA approval was rejected and the product discontinued after the literature search was completed. This search covered several treatment types including monotherapy versus combination therapy, monotherapy versus another drug (MTX or biologic therapy), or monotherapy versus placebo for each medication.

\section{Abatacept Monotherapy}

Six publications comprising two RCTs provided data on the efficacy of ABA monotherapy (Table 2) [18-23]. When ABA monotherapy was compared with ABA + MTX combination therapy in the AVERT study of MTX-naïve patients [18-22], ABA + MTX combination therapy showed higher rates of disease activity score in
28 joints (DAS28) [C-reactive protein (CRP)]defined remission and other efficacy outcomes than ABA monotherapy. When ABA monotherapy was compared with MTX monotherapy, a similar proportion of patients achieved DAS28(CRP)-defined remission at 12 months of treatment [subcutaneous (sc) ABA: 48/113 (42.5\%) versus MTX: 52/115 (45.2\%)], although DAS28(CRP)-defined remission rates were numerically higher for $\mathrm{ABA}$ monotherapy at early time points. Additionally, ABA monotherapy demonstrated numerically higher ACR20/50/70 rates versus MTX over time [18]. Compared with placebo, intravenous (iv) ABA $(10 \mathrm{mg} / \mathrm{kg})$ was associated with improvement in ACR20/50/70 responses, tender and swollen joint counts, patient assessment of disease activity, physician assessments of pain/ disease activity, and CRP and erythrocyte sedimentation rate (ESR) scores in one 24-week study in csDMARD-U/I patients [23].

\section{Adalimumab Monotherapy}

Ten publications comprising nine RCTs, predominantly in csDMARD-U/I patients, provided data on the efficacy of ADA monotherapy (Table 2). Only the PREMIER study in MTXnaïve patients compared ADA + MTX combination therapy to ADA and MTX monotherapies [24]. After 104 weeks of treatment, ACR20/ 50/70 response rates and DAS28(CRP) remission rates were significantly higher with ADA + MTX combination therapy than with ADA monotherapy (all $P<0.001$ ), while ADA and MTX monotherapies were similar. Treatment discontinuation due to lack of efficacy was higher with ADA monotherapy than with MTX monotherapy or ADA + MTX combination therapy [24].

Compared with placebo, sc ADA monotherapy was associated with statistically significant improvements in ACR20/50/70 compared with placebo over $12-26$ weeks in two studies $[25,26]$; a third study also showed improvements in ACR20/50/70 compared with placebo over 12 weeks although this was non-significant [27]. A fourth study showed a rapid (2-week) clinical improvement in DAS with ADA versus placebo 


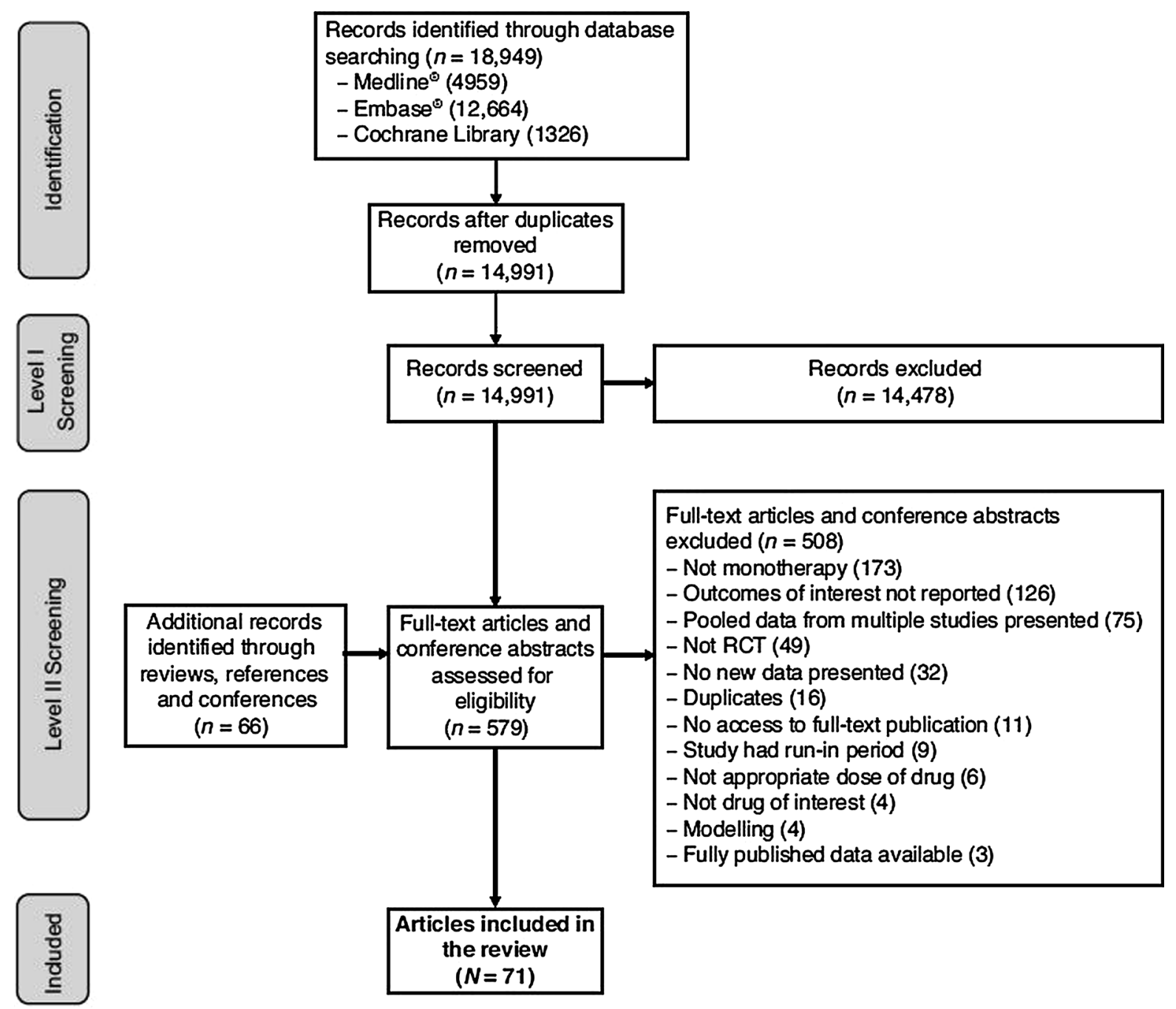

Fig. 1 Screening process

[28]. One study of ADA versus placebo reported that treatment discontinuation due to lack of efficacy was greater in the placebo group compared with the ADA monotherapy groups (significance not reported) [26].

Seven studies compared sc ADA with another treatment [24, 26, 27, 29-33]. Two publications from the ADACTA study compared sc ADA head-to-head with iv TCZ. ACR20/50/70 response rates and improvements in DAS28, physician global assessment (PGA), and the number of patients in DAS28(ESR) remission, Clinical Disease Activity Index (CDAI) remission, and with a good EULAR response were significantly greater with TCZ than ADA
$[29,30]$. Two publications from the MONARCH study compared sc ADA head-to-head with sc SRL [31, 32]. At 24 weeks, ACR20/50/70 response rates and improvements in Health Assessment Questionnaire (HAQ) score, DAS28(ESR) remission, and CDAI remission were significantly greater with SRL than ADA [31]. One publication from the SIRROUND-H study compared sc ADA with sc SRK [33]. ACR20/50 response rates were similar for ADA and SRK; however, patients receiving $100 \mathrm{mg}$ once every 2 weeks (q2w) SRK [but not $50 \mathrm{mg}$ once every 4 weeks $(\mathrm{q} 4 \mathrm{w})$ ] had significantly better DAS28(ESR) change from baseline and DAS28(ESR) remission at 24 weeks than patients 


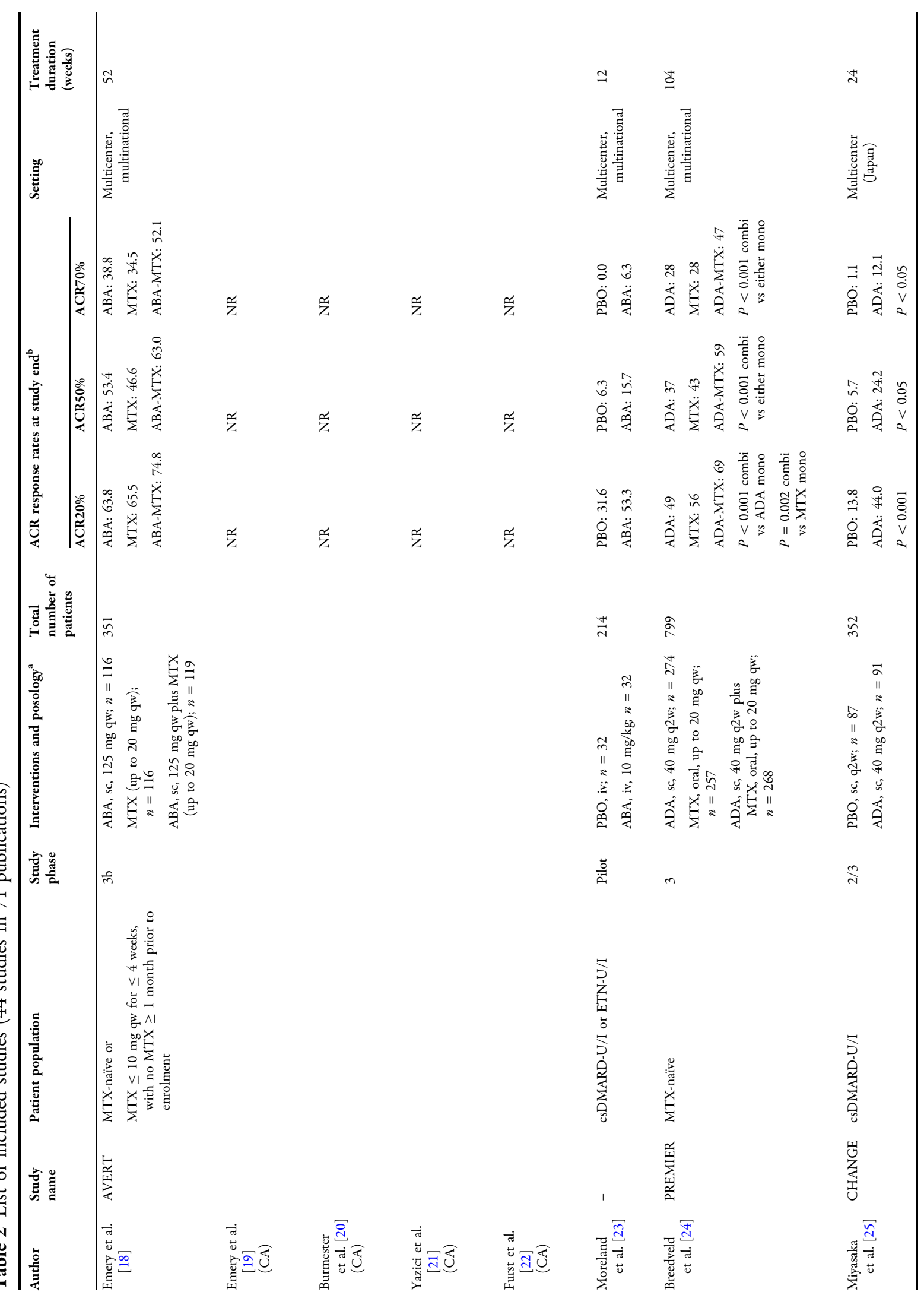




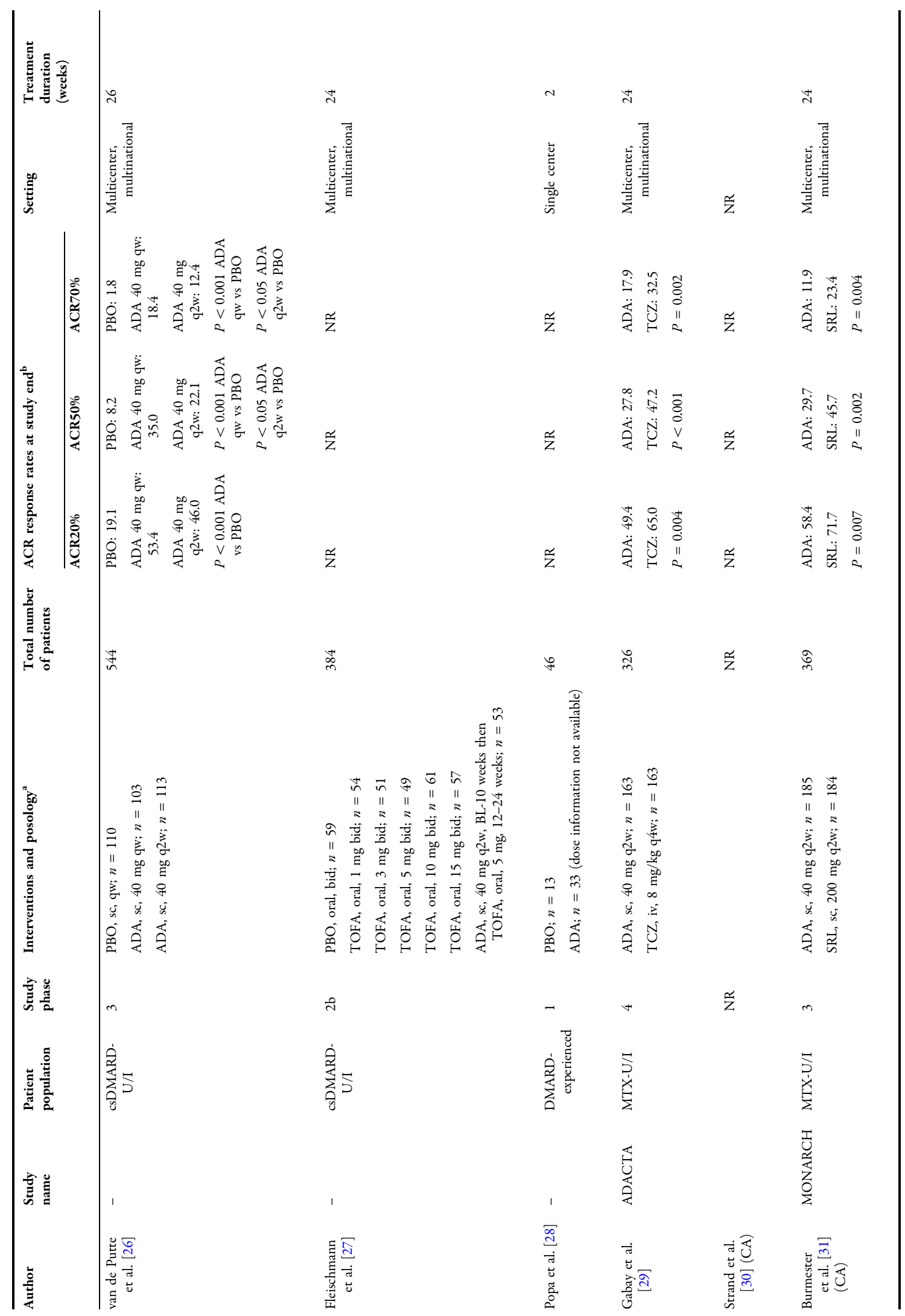




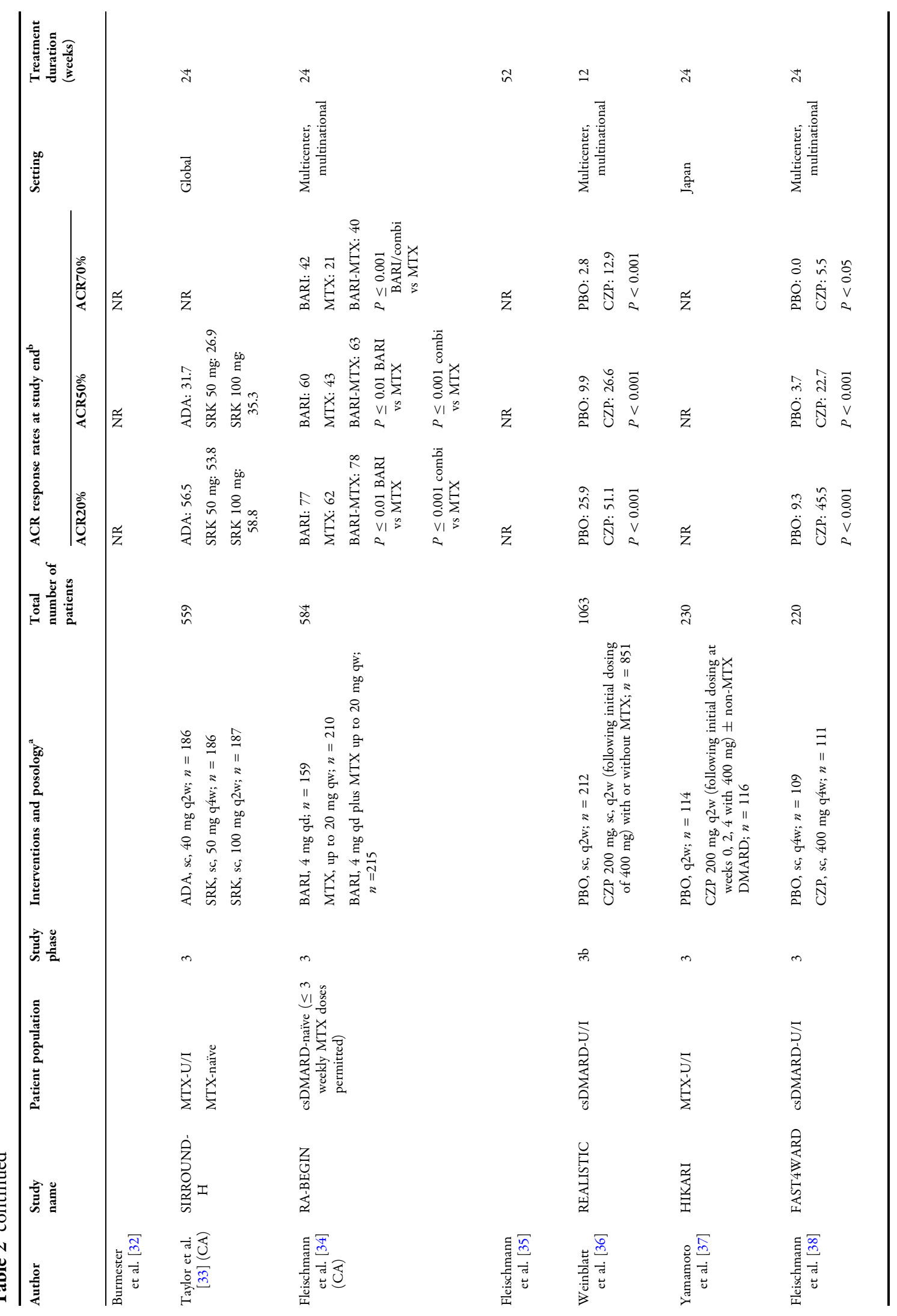




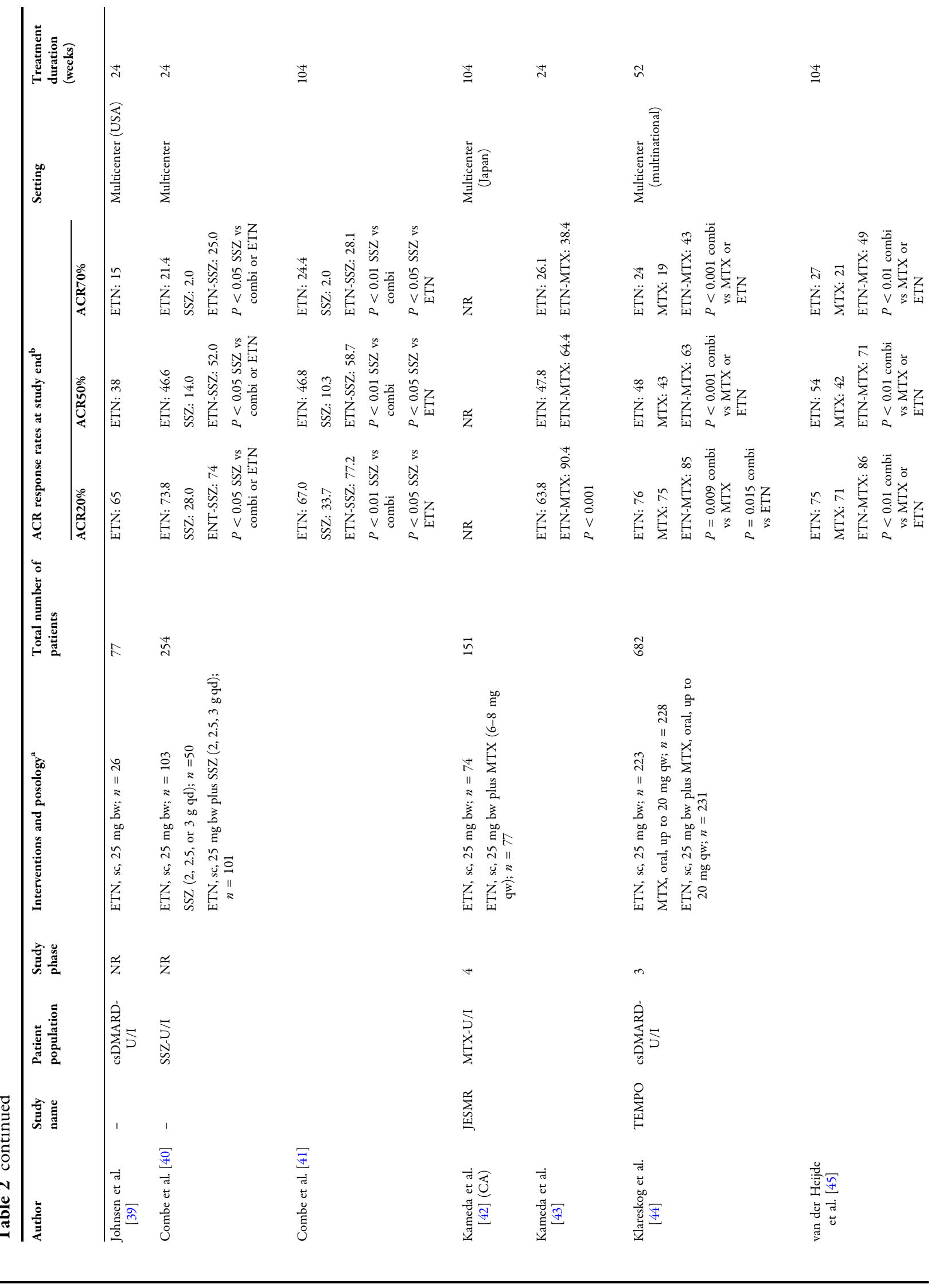




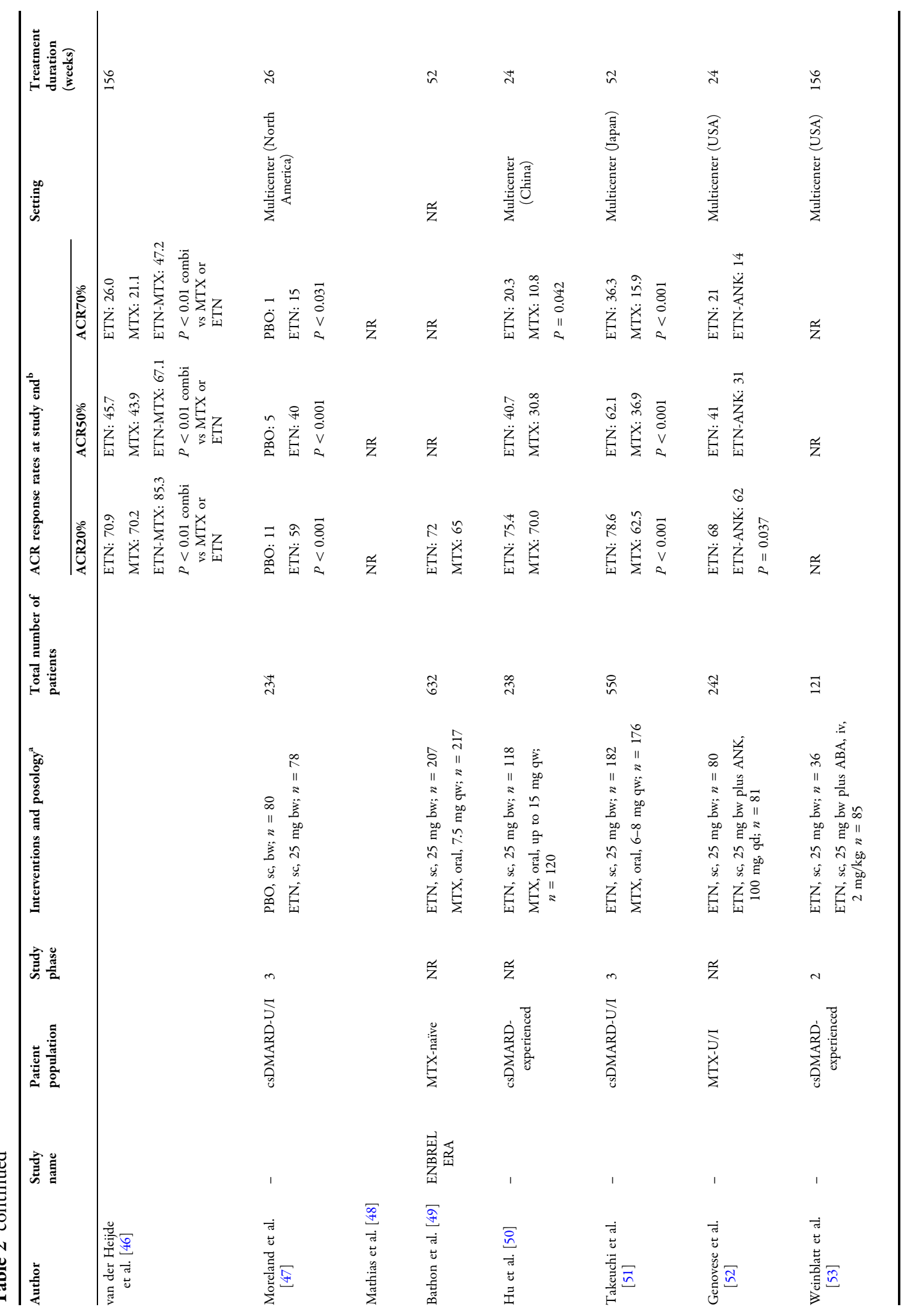




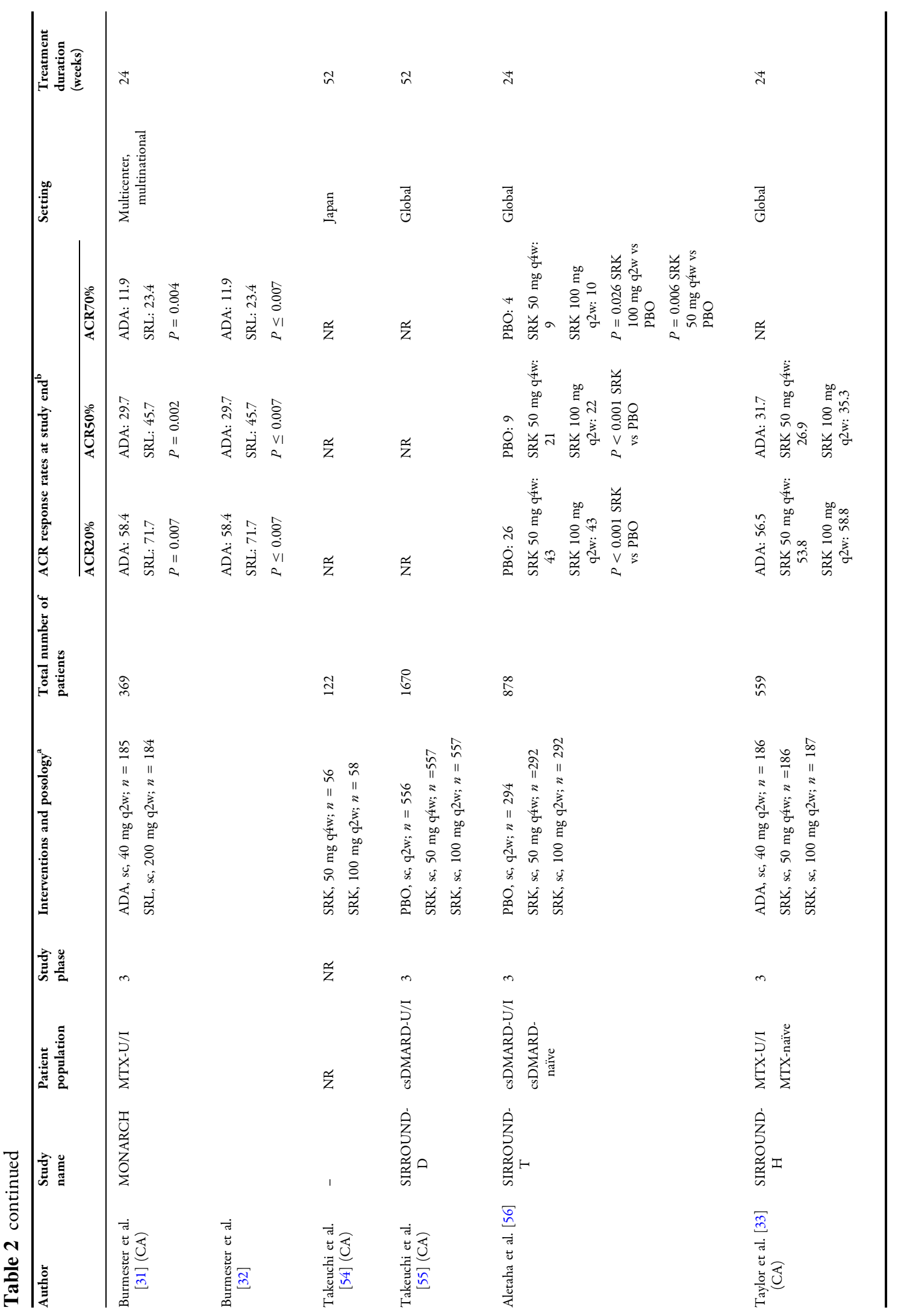




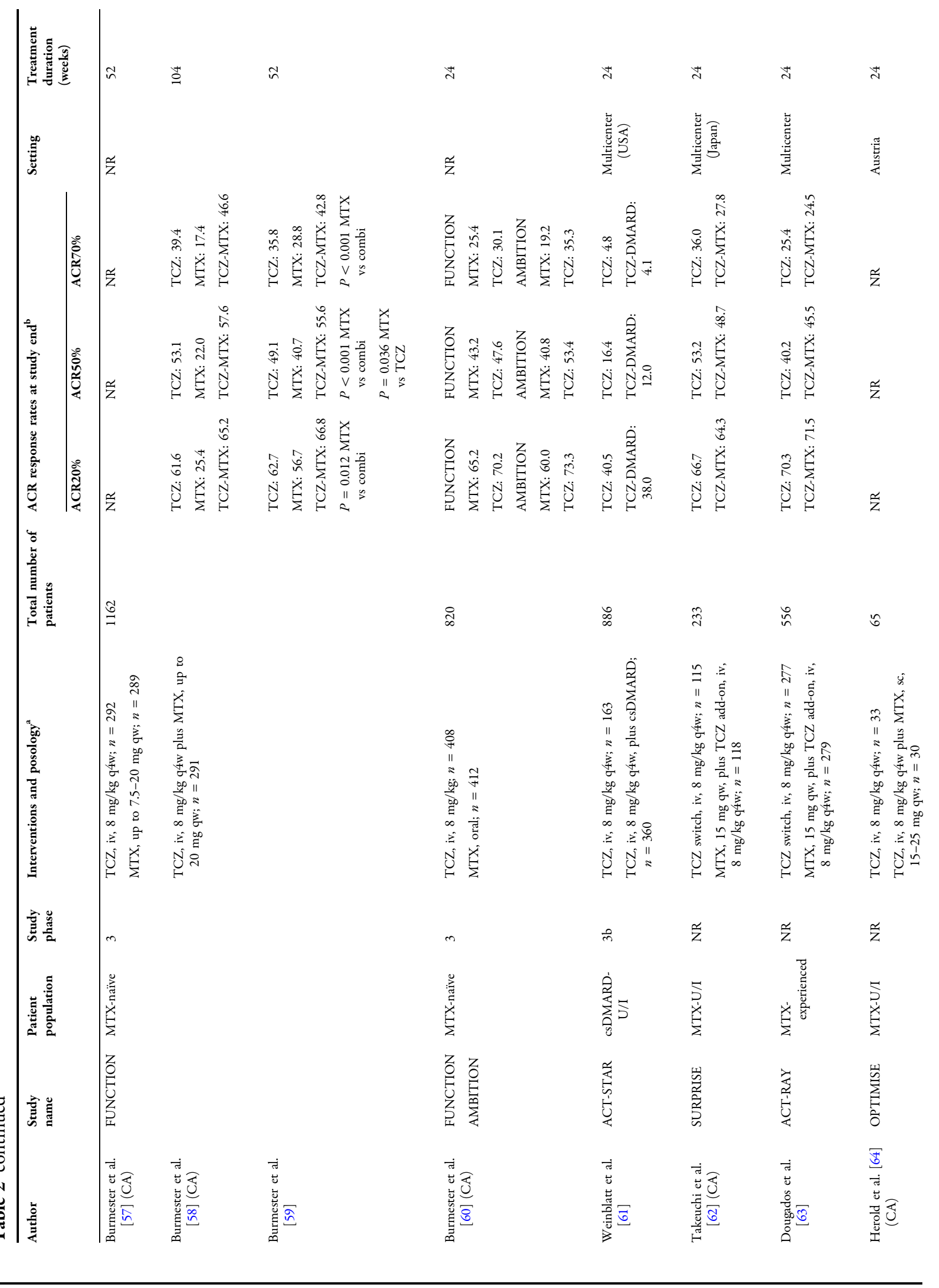




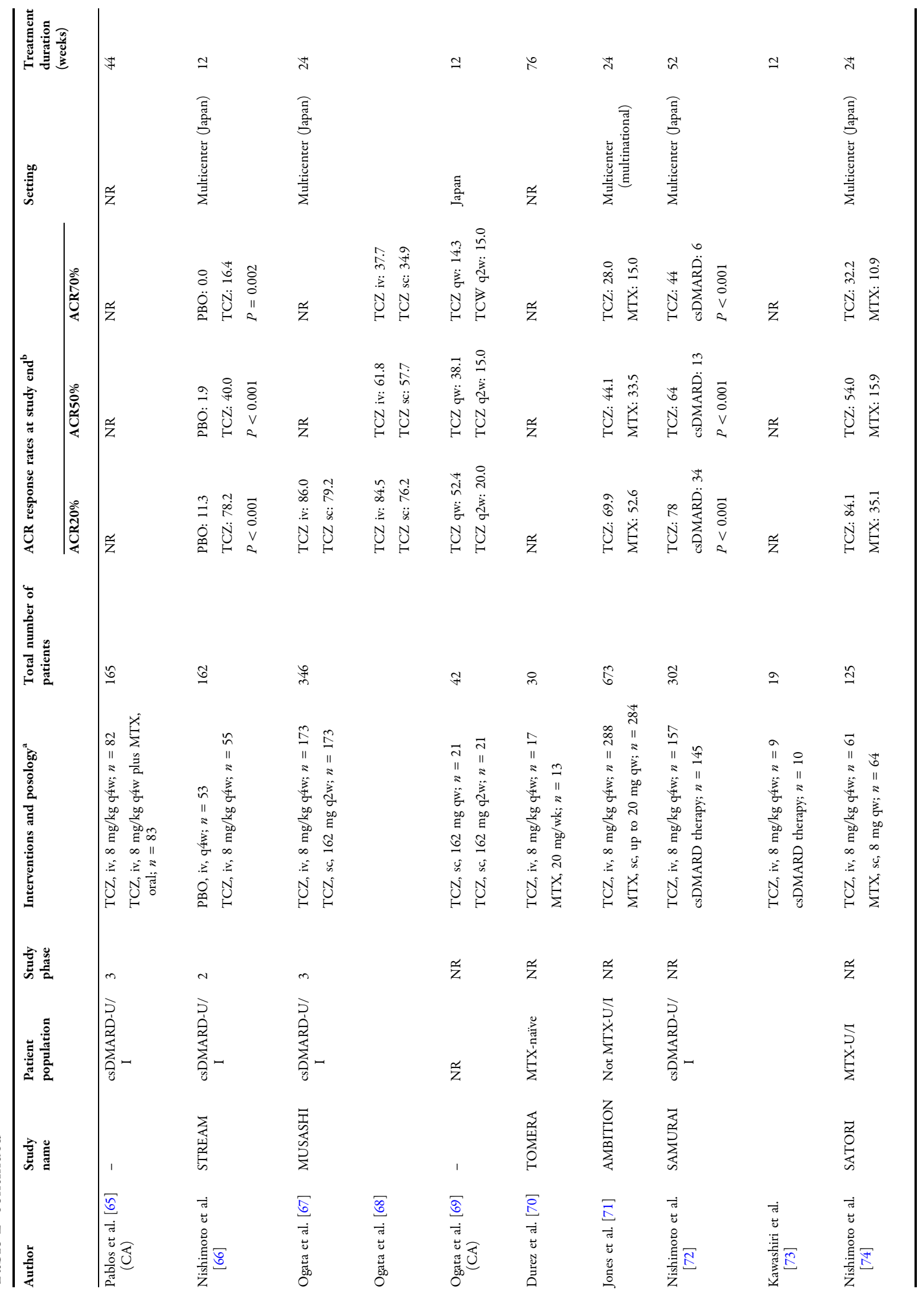




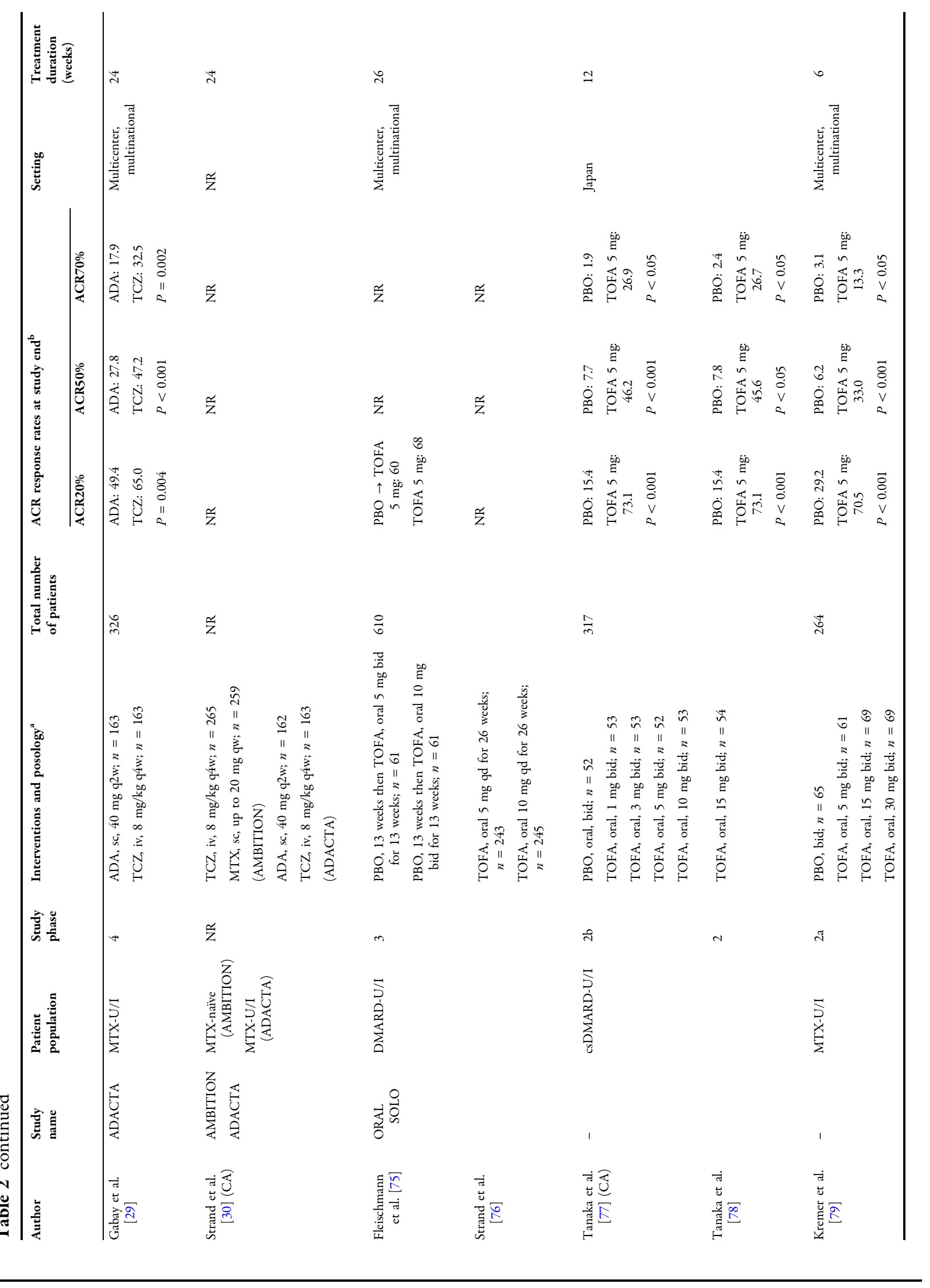




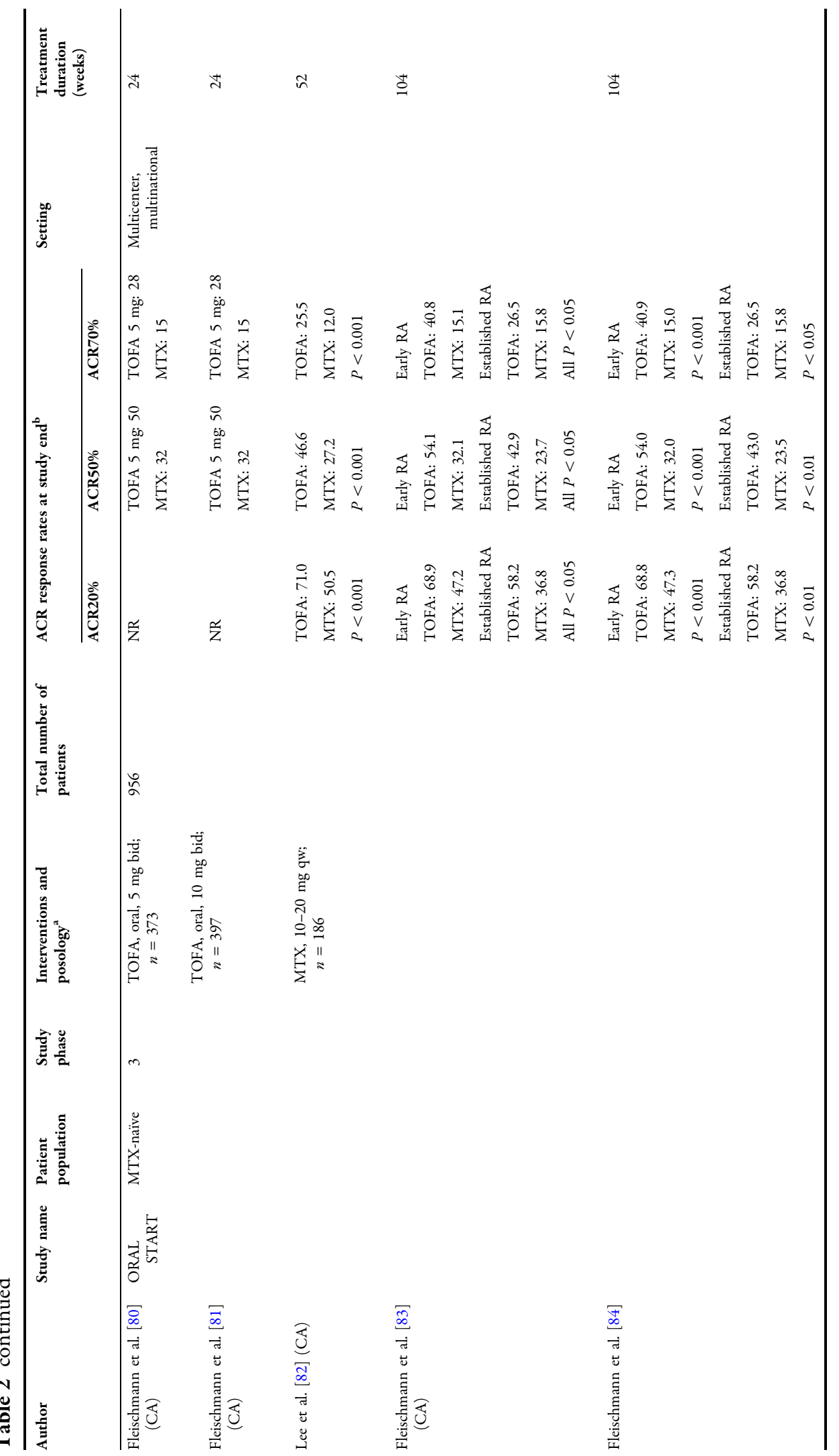




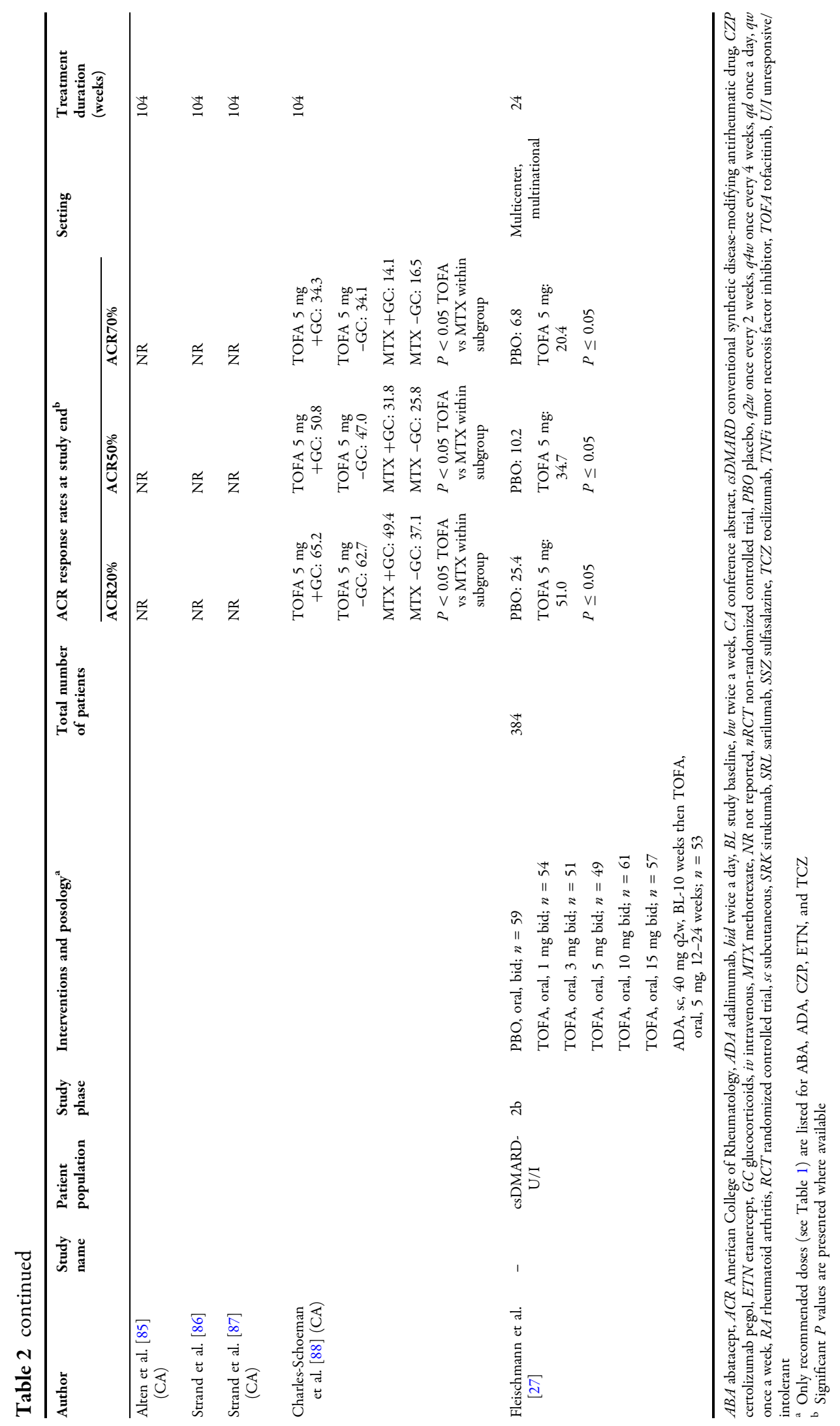


receiving ADA. The final study compared sc ADA to placebo and oral TOFA to placebo [27]. At 12 weeks, ACR/20/50/70 response rates, change in DAS28, and DAS28(ESR) remission rates were higher for $\geq 5 \mathrm{mg}$ twice daily (bid) TOFA than for ADA, although the study was not powered to directly compare the two treatments.

\section{Baricitinib Monotherapy}

Two publications from the RA-BEGIN study in MTX-naïve patients (or patients who had received fewer than 3 weekly MTX doses) provided data on the efficacy of BARI monotherapy (Table 2). Patients receiving BARI + MTX combination therapy or BARI monotherapy were significantly more likely to achieve an ACR20/ 50/70 response than patients receiving MTX $(P \leq 0.01)$, but ACR response rates were similar for BARI + MTX combination therapy and BARI monotherapy. The percentage of patients in DAS28(ESR) remission was significantly higher for BARI + MTX combination therapy $(P \leq 0.01)$ and BARI monotherapy $(P \leq 0.05)$ than for MTX monotherapy [34, 35]. However, change in total Sharp score from study baseline was only significantly higher than MTX monotherapy $(P \leq 0.05)$ for BARI + MTX combination therapy, not for BARI monotherapy [35].

\section{Certolizumab Pegol Monotherapy}

Three publications from three RCTs in csDMARD-U/I patients provided data on the efficacy of CZP monotherapy (Table 2). The REALISTIC study in csDMARD-U/I patients compared patients receiving CZP monotherapy with those receiving CZP + csDMARDs at study baseline. Compared with patients receiving CZP +1 or $\geq 2$ concomitant csDMARDs at baseline, patients receiving CZP monotherapy had lower ACR20/50/70 response rates but slightly greater change in DAS28 (CRP and ESR) scores from baseline, but results were not statistically significant [36]. The HIKARI study of MTX-naïve patients included patients receiving
CZP with or without non-MTX csDMARD therapy. ACR20 response rates at 12 weeks were $67.2 \%$ for CZP monotherapy versus $14.9 \%$ for placebo [37].

Patients receiving CZP monotherapy were more likely to achieve an ACR20/50/70 response than patients receiving placebo [36-38]. Significantly more patients in the placebo group discontinued treatment because of a lack of efficacy than in the CZP monotherapy group $(P<0.001)$ [38]. The REALISTIC study showed that ACR20/50/70 response rates and change in DAS28 (CRP) from baseline were significantly higher with CZP monotherapy than with placebo after 12 weeks of treatment [36].

\section{Etanercept Monotherapy}

Fifteen publications from 10 RCTs, predominantly in csDMARD-U/I patients, provided data on the efficacy of ETN monotherapy (Table 2). The first study demonstrated the efficacy of $25 \mathrm{mg}$ ETN monotherapy taken twice a week, but there was no placebo or active comparator of approved dose in this study [39].

Three studies directly compared ETN monotherapy with ETN + csDMARD combination therapy [40-46]. ACR20/50/70 responses were significantly greater with ETN + MTX combination therapy than with ETN monotherapy at 52 weeks $(P=0.003 /=0.001 /$ $=0.005$ ) [42] and 3 years (all $P<0.01$ ) [46] as were numbers of patients achieving DAS or DAS28 remission [43-46]. In an ETN + sulfasalazine (SSZ) treatment study, combination therapy was not significantly more effective than ETN monotherapy for ACR20/50/70 response rates at 24 or 104 weeks [41], or for mean DAS28 score at 24 weeks, but was significantly more effective for mean DAS28 score at 104 weeks [40, 41].

In a study comparing ETN monotherapy with placebo [47, 48], ACR20/50/70 response rates were significantly higher for ETN than for placebo at 3 and 6 months, as were improvements in Tender Joint Count (TJC), Swollen Joint Count (SJC), HAQ (3 and 6 months), and PGA (12 weeks). At 6 months, significantly more patients receiving placebo had 
discontinued because of a lack of treatment efficacy than patients receiving ETN [47].

Three studies compared the efficacy of ETN monotherapy with csDMARD monotherapy [49-51]: one study was in MTX-naïve patients, one in csDMARD-experienced patients, and one in csDMARD-U/I patients. In these three studies, significantly more patients achieved ACR20/50/70 responses with ETN monotherapy than with MTX over 6 months $(P<0.05)$ [49-51] (although for one study the difference between treatments was only seen with cumulative response over time) [49].

Finally, two studies compared sc ETN monotherapy with either ETN-ANK [52] (6 months) or ETN-ABA [53] (12 months) combination therapy. Neither combination provided treatment benefit over ETN monotherapy $[52,53]$.

\section{Sarilumab Monotherapy}

No publications compared SRL monotherapy with SRL + csDMARD combination therapy. Two publications from the MONARCH study provided data on the efficacy of SRL monotherapy (Table 2) by comparing sc SRL with sc ADA [31, 32]. At 24 weeks, ACR20/50/70 response rates and improvements in HAQ score, DAS28(ESR) remission, and CDAI remission were significantly greater with SRL than ADA monotherapy [31].

\section{Sirukumab Monotherapy}

No publications compared SRK monotherapy with SRK + csDMARD combination therapy. Four publications from four different studies, predominantly in csDMARD-U/I patients, provided data on the efficacy of SRK monotherapy (Table 2). One study in csDMARD-naïve patients comparing two doses of SRK monotherapy showed that more patients achieved ACR20/50/70 responses with $100 \mathrm{mg}$ q2w SRK than with $50 \mathrm{mg}$ q $4 \mathrm{w}$ by 24 weeks, but there was no placebo or active comparator in this study [54]. Two studies compared these same SRK doses with placebo $[55,56]$. More patients achieved ACR20/50 responses,
DAS28(CRP) remission, and improvements in HAQ score with SRK than with placebo at both 16 and 24 weeks, with the two SRK doses being generally comparable $[55,56]$. One publication from the SIRROUND-H study compared sc SRK with sc ADA [33]. ACR20/50 response rates were similar for SRK and ADA; however, patients receiving SRK (50 $\mathrm{mg} \mathrm{q} 4 \mathrm{w}$ and $100 \mathrm{mg} \mathrm{q} 2 \mathrm{w}$ ) had significantly better DAS28(ESR) change from baseline, and patients receiving $100 \mathrm{mg}$ q2w SRK had significantly better DAS28(ESR) remission rates at 24 weeks than patients receiving ADA monotherapy [33].

\section{Tocilizumab Monotherapy}

Twenty publications from 14 RCTs, predominantly in csDMARD-U/I patients, provided data on the efficacy of TCZ monotherapy (Table 2).

Six studies directly compared TCZ monotherapy with TCZ + csDMARD combination therapy [57-65]. In the FUNCTION study of MTX-naïve patients, a greater number of patients achieved ACR20/50/70 and DAS28(ESR) remission with TCZ + MTX combination therapy versus TCZ monotherapy over 1-2 years, and a greater proportion of patients receiving TCZ monotherapy achieved ACR20/ 50/70 and DAS28(ESR) remission versus MTX monotherapy (significance not reported) [57-60]. Five studies compared TCZ + MTX combination therapy with either TCZ monotherapy or TCZ plus placebo (effectively monotherapy) in csDMARD-U/I patients. The unblinded ACT-STAR study compared $8 \mathrm{mg} / \mathrm{kg}$ TCZ monotherapy with TCZ + csDMARD combination therapy ( 4 or $8 \mathrm{mg} / \mathrm{kg}$ ). After 24 weeks, the ACR20/50/70 response rates were similar for TCZ monotherapy and both TCZ + csDMARD combination therapy doses [61]. The SURPRISE study compared TCZ monotherapy with TCZ + MTX. DAS28(ESR) remission rates were higher with combination therapy than with TCZ monotherapy $(P=0.04)$, but differences between ACR20/50/70 response rates and CDAI and Simple Disease Activity Index (SDAI) remission rates between groups were not significant [62]. The double-blind ACT-RAY study treated patients with either TCZ + placebo or 
TCZ + MTX for 24 weeks. DAS28(ESR) remission rates and ACR20/50/70 response rates were similar for TCZ + MTX and TCZ + placebo (differences were not significant) [63]. The OPTIMISE study treated all patients with TCZ + MTX for 12 weeks and then randomized patients to treatment with either TCZ + MTX or TCZ + placebo, but analyzed them on the basis of anti-cyclic citrullinated peptide status rather than treatment group. DAS28 and CDAI changed significantly from baseline to week 12 $(P<0.001)$, but did not change from week 12 to 24 [64]. The final study treated all patients with TCZ + MTX for 16 weeks and then randomized patients to either continue TCZ + MTX or switch to TCZ + placebo with a follow-up at 28 weeks. DAS28(ESR) remission rates were similar for both groups at 28 weeks [65].

The STREAM study was the only study to compare iv TCZ to placebo. The number of patients achieving ACR20/50/70 was greater with TCZ monotherapy than with placebo, and treatment discontinuation due to lack of efficacy was higher with placebo than with TCZ monotherapy over 3 months [66].

The MUSASHI RCT (and open-label extension) compared the efficacy of iv TCZ versus sc $\mathrm{TCZ}$ in Japanese patients. At 24 weeks, more patients achieved ACR20/50/70 responses, DAS28(ESR) remission, and CDAI remission with iv TCZ monotherapy than with sc TCZ monotherapy $[67,68]$. Another study in Japanese patients, focusing on patients with an inadequate response to $\mathrm{q} 2 \mathrm{w}$ dosing, compared two different SC TCZ dosing frequencies. Change in DAS28(ESR) was significantly greater over 12 weeks with qw dosing than with q2w dosing [69].

Four studies were of TCZ monotherapy versus a csDMARD. The TOMERA [70] study of csDMARD-naïve patients, and the AMBITION study where $89 \%$ of patients were csDMARDnaïve [30, 60, 71], compared TCZ with MTX. In the TOMERA study, more patients achieved DAS28(CRP), SDAI, ACR-EULAR Booleandefined remission, and an SJC of 0 with TCZ than with MTX at 6 months [DAS28(CRP) remission non-significant, all others $P \leq 0.01$ ]; after 6 months, all patients received MTX [70]. The AMBITION study compared TCZ monotherapy with MTX in patients who had not previously failed MTX treatment. Significantly more patients achieved ACR20/50/70 responses with TCZ than MTX [71], and a higher proportion of patients receiving TCZ achieved DAS28(ESR) remission compared with those receiving MTX, although this difference was non-significant [60]. In addition, TCZ monotherapy was more effective than MTX in improving patient-reported outcomes (PROs) including CDAI and HAQ-disability index score [30]. The SAMURAI [72, 73] and SATORI [74] studies of TCZ monotherapy versus csDMARD were in csDMARD-U/I patients. In both studies, the numbers of patients achieving ACR20/50/70 responses were higher for TCZ monotherapy versus csDMARD [72, 74].

Finally, the ADACTA head-to-head study of TCZ monotherapy versus ADA monotherapy in csDMARD-U/I patients reported a significantly greater number of patients achieving ACR20/ 50/70 (all $P<0.005$ ), DAS28(ESR) remission $(P<0.001)$, CDAI remission $(P=0.04)$, and good EULAR response $(P<0.001)$ with TCZ monotherapy than with ADA monotherapy [29]. In addition, improvements in PROs were greater with TCZ than ADA monotherapy for all parameters assessed [30].

\section{Tofacitinib Monotherapy}

No publications compared TOFA monotherapy with TOFA + csDMARD combination therapy. Fifteen publications comprising five RCTs provided data on the efficacy of TOFA monotherapy (Table 2). The majority of studies were in csDMARD-U/I patients and compared TOFA monotherapy with placebo.

One phase 3 study in DMARD-U/I patients compared 5 and $10 \mathrm{mg}$ bid TOFA with placebo, using a study design where patients were treated for 3 months, and then patients receiving placebo were blindly re-randomized to 5 or $10 \mathrm{mg}$ bid TOFA for a further 3 months. At 3 months in the ORAL SOLO study [75, 76], ACR20/50/70 response rates were significantly higher at 3 months for both TOFA doses versus placebo [all $P<0.001$ except ACR70 $5 \mathrm{mg}$ bid $(P=0.003)]$ [75]. The percentage of patients 
achieving DAS28(ESR) remission was numerically higher for both TOFA doses versus placebo but the between-group differences were not statistically significant [75]. After the first 3 months of treatment, patients receiving TOFA monotherapy also reported statistically significant and clinically meaningful improvements in several PROs compared with patients receiving placebo [76].

The two other studies of TOFA monotherapy versus placebo were phase 2 dose-ranging studies comparing a wider range of TOFA doses. The first study compared five doses of TOFA $(1,3,5$, 10 , and $15 \mathrm{mg}$ bid) with placebo. ACR20 response rates were statistically significantly higher with TOFA monotherapy than placebo at 12 weeks $(P<0.05$, all doses $)$ ACR50/70 response rates and DAS28(ESR) remission rates were also significantly greater with TOFA (doses $\geq 5 \mathrm{mg}$ bid) than placebo at 12 weeks $(P<0.05)[77,78]$. The second study compared TOFA 5/15/30 mg bid with placebo. By 6 weeks, ACR20/50/70 response rates were significantly higher with TOFA monotherapy than placebo [all $P<0.001$ except for ACR70, $5 \mathrm{mg}$ bid $(P<0.05)]$, and the percentage of patients achieving a EULAR good response was higher for all TOFA doses than for placebo [79].

One placebo-controlled trial of TOFA monotherapy also compared $1,3,5,10$, and $15 \mathrm{mg}$ bid TOFA monotherapy and ADA (40 mg $\mathrm{q} 2 \mathrm{w})$ monotherapy with placebo. At 12 weeks, ACR20 response rates were significantly higher for $3-15 \mathrm{mg}$ TOFA than for placebo $(3 \mathrm{mg}$, $P \leq 0.05 ; \quad 5 / 10 / 15 \mathrm{mg}, \quad P<0.001) \quad$ and DAS28(ESR) remission was significantly higher for $\geq 10 \mathrm{mg}$ TOFA than for placebo $(P \leq 0.05)$. ACR50/70 response rates were significantly higher in the TOFA dose groups compared with placebo at 12 weeks [in those receiving $\geq 5$ (ACR50) and $\geq 10 \mathrm{mg}$ (ACR70) bid] and 24 weeks [in those receiving $\geq 3$ (ACR50) and $\geq 5 \mathrm{mg}$ (ACR70) bid] [27].

The ORAL START [80-88] study in MTXnaïve patients compared TOFA monotherapy (5 and $10 \mathrm{mg}$ bid) with MTX monotherapy (10-20 mg/week). The number of patients achieving ACR20/50/70 (all $P<0.0001$ ) and DAS28(ESR) remission $(5 \mathrm{mg}, P<0.05 ; 10 \mathrm{mg}$, $P<0.001)$ at 6 months was shown to be significantly greater with $5 \mathrm{mg}$ and $10 \mathrm{mg}$ TOFA than with MTX [82]. At 104 weeks, ACR20/50/ 70 and DAS28(ESR) remission rates were still significantly higher with TOFA than MTX $(P<0.05$ for most outcomes) [84]. Radiographic outcomes were also significantly improved with TOFA at 24 weeks compared with MTX $(P<0.05)$ [82]. In addition, two subset responder analyses showed that a greater proportion of patients achieved other clinical outcomes with TOFA, including SDAI and CDAI low disease activity and remission, than with MTX at 6 months [80, 81]. Greater improvements from baseline with TOFA versus MTX were observed for PROs including $\mathrm{HAQ}$ at 3, 6, 12, and 24 months $(P<0.05$ for the majority of outcomes assessed) $[85,86]$.

\section{DISCUSSION}

The objective of this study was to evaluate the clinical evidence, published on or before April 11, 2017, regarding the efficacy of the bDMARDs ABA, ADA, CZP, ETN, SRK, SRL, TCZ, and the tsDMARDs TOFA and BARI as monotherapy for the treatment of RA. Comparisons of $b / t s D M A R D s$ with placebo or with a csDMARD consistently showed b/tsDMARDs to be efficacious treatments, regardless of whether patients were csDMARD-naïve or csDMARDintolerant. However, better treatment outcomes were usually achieved when in combination with a csDMARD, and this was observed for all b/tsDMARDs assessed by this review. The benefits observed with the co-administration of a csDMARD such as MTX with a b/tsDMARD have been suggested to result from the effect of MTX to (1) reduce inflammation and radiographic progression, (2) increase the bioavailability of the bDMARD (for ADA and infliximab), and (3) attenuate anti-drug antibodies, all of which may also prolong treatment durability [10]. However, MTX can have a pharmacokinetic interaction with bDMARDs; it has been shown that there is an increased risk of infections with MTX and ADA, CZP, infliximab, and golimumab combination therapy [89] and therefore for some patients, monotherapy may be the preferred treatment option. 
In clinical practice, patients receiving b/tsDMARD monotherapy for RA are either csDMARD-naïve or have previously failed treatment with csDMARD(s). We found that the amount of evidence for the efficacy of $\mathrm{b} /$ tsDMARD monotherapy differs for these two groups of patients.

For csDMARD-naïve patients with RA, there was no evidence to support the use of CZP or SRL as monotherapy. For ABA [18-22], BARI [34, 35], ETN [49], SRK [33], and TOFA [80-88], the efficacy of each treatment as monotherapy was supported by only a single study. For ABA, BARI, ETN, and TOFA, monotherapy was more efficacious than MTX. For SRK, monotherapy was shown to be more efficacious than ADA for some outcomes, but not others. For ADA $[24,33]$ and TCZ [57-60, 70, 71], the efficacy of each treatment as monotherapy was supported by two and three studies, respectively. ADA monotherapy efficacy was similar to MTX, while comparisons with SRK only showed superiority for some outcomes. TCZ monotherapy was more efficacious than MTX. TCZ + csDMARD combination therapy was more efficacious than TCZ monotherapy in this patient population [57-60].

For csDMARD-U/I patients with RA, most of the $b / t s D M A R D s$ assessed in this study were more efficacious in combination with MTX than as monotherapy. No studies in BARI were conducted in csDMARD-U/I patients. For ABA [23] and SRL [31, 32], the efficacy of each treatment as monotherapy was supported by only a single study. ABA monotherapy was more efficacious than MTX and SRL monotherapy was more efficacious than ADA in this patient population. For CZP, monotherapy efficacy was supported by three studies [36-38] but was not shown to be as efficacious as combination therapy. For SRK [33, 54-56] and TOFA [27, 75-79], monotherapy efficacy was supported by four studies. SRK was more efficacious than placebo but comparisons with ADA only showed superiority for some outcomes. TOFA was more efficacious than placebo and ADA (although only one study had both TOFA and ADA treatment arms and this study was not designed to directly compare the two treatments). The largest number of studies in
csDMARD-U/I patients were available for ADA, ETN, and TCZ. ADA monotherapy was consistently more efficacious than placebo, but no comparisons were made with MTX. ADA monotherapy was less efficacious than other $\mathrm{b} /$ tsDMARDs in head-to-head comparisons [25-33]. ETN and TCZ monotherapies were consistently more efficacious than placebo and csDMARDs. These two treatments also compared ETN and TCZ monotherapy with treatment in combination with csDMARDs. ETN combination therapy was more efficacious than ETN monotherapy [42-46]. For TCZ in csDMARD-U/I patients, TCZ monotherapy was not inferior to TCZ + csDMARD combination therapy [61, 64, 65]. Previous SLRs of b/tsDMARD monotherapy in patients with an inadequate response to csDMARDs have also reported similar efficacy of TCZ and TCZ + MTX for ACR responses [13] and PROs [14].

Overall, the data reviewed in this SLR suggest that several $b /$ tsDMARDs can be used as monotherapy, although several studies were in csDMARD-naïve patients, which is not generalizable to usual clinical practice. Better treatment outcomes were usually achieved when in combination with a csDMARD, so a key question for any clinician considering treating a patient with monotherapy rather than combination therapy is the efficacy of which treatment will diminish the least without concomitant csDMARDs. No head-to-head monotherapy versus combination therapy studies of TCZ [57-59, 61, 63, 64], or the only study of BARI [34], showed statistically significant differences in ACR20 responses between combination and monotherapy while both the JESMR [42, 43] and TEMPO [44-46] studies of ETN, the PREMIER study of ADA [24], and the AVERT study of ABA [18] all showed statistically significant differences in ACR20 responses between combination and monotherapy. The PREMIER study also showed significant differences in number of patients in DAS28(CRP) remission between combination and monotherapy, while the TEMPO and Combe et al. [40, 41] ETN studies showed significant differences in mean DAS28 score between combination and monotherapy. This could suggest that BARI and TCZ might be more efficacious as monotherapy than ABA, ADA, or 
ETN. However, more head-to-head studies of all these treatments are needed to further evaluate this, as the benefits of combination therapy over monotherapy were examined by at most three head-to-head studies for each treatment (with the exception of TCZ, where seven studies compared combination and monotherapy), and for SRL, SRK, and TOFA no such studies were identified.

This analysis had some limitations. No new information regarding in which order b/tsDMARDs should be used as monotherapy, or why one should be selected for use over others, is presented. Another limitation is the heterogeneity observed between study characteristics that are modifiers of the treatment effects, and heterogeneity resulting from inclusion of studies from several different countries. Previous analyses of bDMARD monotherapy have specifically excluded studies in exclusively non-Western populations [13] but this did not. Non-Western populations, especially Japan, use lower and possibly suboptimal doses of MTX, limiting the differences between monotherapy and combination therapy. In addition, poor-quality studies were not excluded, although study quality was taken into account when interpreting treatment outcomes. Also, the durability of monotherapy versus combination treatments was not taken into account when evaluating treatment efficacy. Issues such as patient tolerability and acceptability are a reality with DMARDs but are not considered in RCTs. Differential retention may affect whether one drug is used over another in patients receiving monotherapy but this cannot be concluded from this SLR. Also, measures such as ACR20 which capture smaller improvements in disease activity may not differentiate between monotherapy versus combination therapy, but greater measures of improvements such as ACR70 or DAS/DAS28 remission may do so. Safety and cost may also be important in choosing one treatment over another in patients using monotherapy. Finally, this analysis did not address differences in safety outcomes for the studies included, meaning that only the benefit of these treatments, and not the risk/benefit, could be assessed.
The conclusions that can be drawn from this analysis are also limited by the types of studies identified by the search parameters. There were very few head-to-head studies of different $\mathrm{b} / \mathrm{tsDMARDs}$ as monotherapy. Dosing schedules varied and most studies did not compare multiple doses of the b/tsDMARDs being evaluated, meaning that the efficacy of higher doses of these monotherapy treatments could not be assessed. The retention on a specific drug and real-world effectiveness, tolerability, and safety were also not within the scope of this study.

\section{CONCLUSIONS}

The findings of this SLR highlight the benefits of bDMARDs in combination with csDMARDS, and in some instances also in monotherapy. In csDMARD-naïve patients, b/tsDMARD monotherapy was generally more efficacious than csDMARD monotherapy, but b/tsDMARD + csDMARD combination therapy was more efficacious than b/tsDMARD monotherapy. In csDMARD-U/I patients, most of the $b / t s D M A R D s$ assessed in this study were more efficacious than csDMARDs, but were also more efficacious as combination therapy with a csDMARD than as monotherapy. However, in this patient population, TCZ monotherapy was not inferior to TCZ + csDMARD combination therapy. This SLR confirms a favorable efficacy profile of these therapies and emphasizes areas in need of further investigation. There is a need for longer-term head-to-head trials to fully establish positioning of these interventions in the treatment algorithm for RA.

\section{ACKNOWLEDGEMENTS}

Funding. The systematic literature review to support this article and the article processing charges were funded by Pfizer, Rome, Italy. All authors had full access to all of the data in this study and take complete responsibility for the integrity of the data and accuracy of the data analysis. 
Medical Writing, Editorial and Other Assistance. The literature search was conducted by Sadiq Lula, Carole Jones, and Catherine Rolland, PhD, of Envision Pharma Group, and was funded by Pfizer. Medical writing support for the article was provided by Lorna Forse, PhD, of Engage Scientific Solutions and was funded by Pfizer.

Authorship. All named authors meet the International Committee of Medical Journal Editors (ICMJE) criteria for authorship for this article, take responsibility for the integrity of the work as a whole, and have given their approval for this version to be published.

Disclosures. Paul Emery has received research grants paid to his employer from AbbVie, BMS, Pfizer, MSD, and Roche; consultant fees from BMS, AbbVie, Pfizer, MSD, Novartis, Roche, and UCB; and has undertaken clinical trials and provided expert advice to Pfizer, MSD, AbbVie, BMS, UCB, Roche, Novartis, Samsung, Sandoz, and Lilly. Janet Pope has received research grants from Bayer, Merck, BMS, Roche, GSK, and Seattle Genetics; consultant fees/ honoraria from AbbVie, Actelion, Amgen, BMS, GSK, Lilly, Merck, Novartis, Pfizer, Roche, Sanofi, Sandoz, and UCB; payment for lectures including service on speakers' bureaus from Amgen, BMS, Merck, Novartis, Pfizer, Sanofi, Sandoz, and UCB; and has provided expert testimony for AbbVie. During the development of the systematic literature review and manuscript, Sadiq Lula was an employee of Envision Pharma Group, who were paid consultants to Pfizer in connection with the development of the systematic literature review report that forms the basis of this manuscript. He was not compensated for his role in the development of this manuscript. Sadiq Lula is now an employee of IQVIA. Ralph Lippe is an employee of and stockholder in Pfizer. Ryan DeMasi is an employee of and stockholder in Pfizer. Blerina Kola is an employee of and stockholder in Pfizer. Klaus Kruger has nothing to disclose.

Compliance with Ethics Guidelines. This article is based on previously conducted studies and does not contain any studies with human participants or animals performed by any of the authors.

Data Availability. All data generated or analyzed during this study are included in this published article/as supplementary information files.

Open Access. This article is distributed under the terms of the Creative Commons Attribution-NonCommercial 4.0 International License (http://creativecommons.org/licenses/ by-nc/4.0/), which permits any noncommercial use, distribution, and reproduction in any medium, provided you give appropriate credit to the original author(s) and the source, provide a link to the Creative Commons license, and indicate if changes were made.

\section{REFERENCES}

1. Smolen JS, van der Heijde D, Machold KP, Aletaha D, Landewe R. Proposal for a new nomenclature of disease-modifying antirheumatic drugs. Ann Rheum Dis. 2014;73:3-5.

2. European Medicines Agency. Medicines. 2017. http://www.ema.europa.eu/ema/index.jsp?curl=pag es/includes/medicines/medicines_landing_page.jsp. Accessed 13 Feb 2018.

3. US Food and Drug Administration. Drugs@FDA: FDA approved drug products. 2017. https://www.access data.fda.gov/scripts/cder/daf/index.cfm. Accessed 13 Feb 2018.

4. Clarke T. FDA declines to approve J\&J arthritis drug sirukumab. Reuters. September 22, 2017.

5. Smolen JS, Landewe R, Bijlsma J, et al. EULAR recommendations for the management of rheumatoid arthritis with synthetic and biological diseasemodifying antirheumatic drugs: 2016 update. Ann Rheum Dis. 2017;76:960-77.

6. Jørgensen TS, Kristensen LE, Christensen R, et al. Effectiveness and drug adherence of biologic monotherapy in routine care of patients with rheumatoid arthritis: a cohort study of patients registered in the Danish biologics registry. Rheumatology (Oxford). 2015;54:2156-65.

7. Choy E, Taylor P, McAuliffe S, Roberts K, Sargeant I. Variation in the use of biologics in the management 
of rheumatoid arthritis across the UK. Curr Med Res Opin. 2012;28:1733-41.

8. Aaltonen KJ, Turunen JH, Sokka T, Puolakka K, Valleala $\mathrm{H}$. A survey on the medication adherence to methotrexate among rheumatoid arthritis patients treated with self-administered biologic drugs. Clin Exp Rheumatol. 2016;34:694-7.

9. Yazici Y, Shi N, John A. Utilization of biologic agents in rheumatoid arthritis in the United States: analysis of prescribing patterns in 16,752 newly diagnosed patients and patients new to biologic therapy. Bull NYU Hosp Jt Dis. 2008;66:77-85.

10. Emery P, Sebba A, Huizinga TW. Biologic and oral disease-modifying antirheumatic drug monotherapy in rheumatoid arthritis. Ann Rheum Dis. 2013;72:1897-904.

11. Engel-Nitz NM, Ogale S, Kulakodlu M. Use of antitumor necrosis factor therapy: a retrospective study of monotherapy and adherence to combination therapy with non-biologic disease-modifying antirheumatic drugs. Rheumatol Ther. 2015;2:127-39.

12. Soliman MM, Ashcroft DM, Watson KD, et al. Impact of concomitant use of DMARDs on the persistence with anti-TNF therapies in patients with rheumatoid arthritis: results from the British Society for Rheumatology Biologics Register. Ann Rheum Dis. 2011;70:583-9.

13. Buckley F, Finckh A, Huizinga TW, Dejonckheere F, Jansen JP. Comparative efficacy of novel DMARDs as monotherapy and in combination with methotrexate in rheumatoid arthritis patients with inadequate response to conventional DMARDs: a network meta-analysis. J Manag Care Spec Pharm. 2015;21:409-23.

14. Jansen JP, Buckley F, Dejonckheere F, Ogale S. Comparative efficacy of biologics as monotherapy and in combination with methotrexate on patient reported outcomes (PROs) in rheumatoid arthritis patients with an inadequate response to conventional DMARDs-a systematic review and network meta-analysis. Health Qual Life Outcomes. 2014;12:102.

15. Tarp S, Furst DE, Dossing A, et al. Defining the optimal biological monotherapy in rheumatoid arthritis: a systematic review and meta-analysis of randomised trials. Semin Arthritis Rheum. 2017;46:699-708.

16. Jadad AR, Moore RA, Carroll D, et al. Assessing the quality of reports of randomized clinical trials: is blinding necessary? Control Clin Trials. 1996;17:1-12.

17. Downs $\mathrm{SH}$, Black N. The feasibility of creating a checklist for the assessment of the methodological quality both of randomised and non-randomised studies of health care interventions. J Epidemiol Community Health. 1998;52:377-84.

18. Emery P, Burmester GR, Bykerk VP, et al. Evaluating drug-free remission with abatacept in early rheumatoid arthritis: results from the phase $3 \mathrm{~b}$, multicentre, randomised, active-controlled AVERT study of 24 months, with a 12-month, double-blind treatment period. Ann Rheum Dis. 2015;74:19-26.

19. Emery P, Burmester GR, Bykerk VP, et al. Induction of clinical remission followed by drug free withdrawal with abatacept combination and monotherapy in early RA: results from the AVERT study over 18 months [abstract]. Ann Rheum Dis. 2014;73:69.

20. Burmester G, Furst DE, Combe BG, et al. Stringent criteria for low disease activity and remission after 12 months of treatment, and after treatment withdrawal, with abatacept monotherapy, abatacept with methotrexate or methotrexate alone in early rheumatoid arthritis. Arthritis Rheumatol. 2014;66:S1076-S.

21. Yazici Y, Gandhi KK, Alemao E, Furst DE. Routine assessment of patient index data 3 (RAPID3)defined remission is as stringent as ACR/EULAR Boolean-defined remission in a clinical trial of patients with early rheumatoid arthritis treated with abatacept [abstract]. Arthritis Rheumatol. 2015;67:1644.

22. Furst DE, Bykerk VP, Burmester GR, et al. Treatment effects and minimal clinically important differences in patient-reported outcomes following treatment and withdrawal of abatacept, methotrexate or combination therapy in patients with early rheumatoid arthritis [abstract]. Ann Rheum Dis. $2015 ; 74: 1044$.

23. Moreland LW, Alten R, Van den Bosch F, et al. Costimulatory blockade in patients with rheumatoid arthritis: a pilot, dose-finding, double-blind, placebo-controlled clinical trial evaluating CTLA4Ig and LEA29Y eighty-five days after the first infusion. Arthritis Rheum. 2002;46:1470-9.

24. Breedveld FC, Weisman MH, Kavanaugh AF, et al. The PREMIER study: a multicenter, randomized, double-blind clinical trial of combination therapy with adalimumab plus methotrexate versus methotrexate alone or adalimumab alone in patients with early, aggressive rheumatoid arthritis who had not had previous methotrexate treatment. Arthritis Rheum. 2006;54:26-37.

25. Miyasaka N, Investigators CS. Clinical investigation in highly disease-affected rheumatoid arthritis patients in Japan with adalimumab applying standard and general evaluation: the CHANGE study. Mod Rheumatol. 2008;18:252-62. 
26. van de Putte LB, Atkins C, Malaise M, et al. Efficacy and safety of adalimumab as monotherapy in patients with rheumatoid arthritis for whom previous disease modifying antirheumatic drug treatment has failed. Ann Rheum Dis. 2004;63:508-16.

27. Fleischmann R, Cutolo $\mathrm{M}$, Genovese $\mathrm{MC}$, et al. Phase IIb dose-ranging study of the oral JAK inhibitor tofacitinib (CP-690,550) or adalimumab monotherapy versus placebo in patients with active rheumatoid arthritis with an inadequate response to disease-modifying antirheumatic drugs. Arthritis Rheum. 2012;64:617-29.

28. Popa C, Netea MG, Radstake $T$, et al. Influence of anti-tumour necrosis factor therapy on cardiovascular risk factors in patients with active rheumatoid arthritis. Ann Rheum Dis. 2005;64:303-5.

29. Gabay C, Emery P, van Vollenhoven R, et al. Tocilizumab monotherapy versus adalimumab monotherapy for treatment of rheumatoid arthritis (ADACTA): a randomised, double-blind, controlled phase 4 trial. Lancet. 2013;381:1541-50.

30. Strand V, Lampl K, Birchwood C, et al. Patientreported outcomes in two randomized, controlled trials (RCTs) in patients with rheumatoid arthritis (RA) treated with tocilizumab (TCZ) monotherapy compared with methotrexate (MTX) or adalimumab (ADA). Arthritis Rheumatol. 2016;68:2515.

31. Burmester G, Lin Y, Patel R, et al. Efficacy and safety of sarilumab versus adalimumab in a phase 3, randomized, double-blind, monotherapy study in patients with active rheumatoid arthritis with intolerance or inadequate response to methotrexate. Arthritis Rheumatol. 2016;68:3221.

32. Burmester GR, Lin Y, Patel R, et al. Efficacy and safety of sarilumab monotherapy versus adalimumab monotherapy for the treatment of patients with active rheumatoid arthritis (MONARCH): a randomised, double-blind, parallel-group phase III trial. Ann Rheum Dis. 2017;76:840-7.

33. Taylor PC, Schiff M, Wang Q, et al. Efficacy and safety of monotherapy with sirukumab, an anti-IL-6 cytokine monoclonal antibody, compared with adalimumab monotherapy in biologic-naive patients with active rheumatoid arthritis: results of a global, randomized, double-blind, parallel-group, phase 3 study [abstract]. Arthritis Rheumatol. 2016;68:3222.

34. Fleischmann R, Takeuchi T, Schlichting DE, et al. Baricitinib, methotrexate, or baricitinib plus methotrexate in patients with early rheumatoid arthritis who had received limited or no treatment with disease-modifying anti-rheumatic drugs (DMARDs): phase 3 trial results. Arthritis Rheumatol. $2015 ; 67: 1045$.
35. Fleischmann R, Schiff M, van der Heijde D, et al. Baricitinib, methotrexate, or combination in patients with rheumatoid arthritis and no or limited prior disease-modifying antirheumatic drug treatment. Arthritis Rheumatol. 2017;69:506-17.

36. Weinblatt ME, Fleischmann R, Huizinga TW, et al. Efficacy and safety of certolizumab pegol in a broad population of patients with active rheumatoid arthritis: results from the REALISTIC phase IIIb study. Rheumatology (Oxford). 2012;51:2204-14.

37. Yamamoto K, Takeuchi T, Yamanaka H, et al. Efficacy and safety of certolizumab pegol without methotrexate co-administration in Japanese patients with active rheumatoid arthritis: the HIKARI randomized, placebo-controlled trial. Mod Rheumatol. 2014;24:552-60.

38. Fleischmann R, Vencovsky J, van Vollenhoven RF, et al. Efficacy and safety of certolizumab pegol monotherapy every 4 weeks in patients with rheumatoid arthritis failing previous disease-modifying antirheumatic therapy: the FAST4WARD study. Ann Rheum Dis. 2009;68:805-11.

39. Johnsen AK, Schiff MH, Mease PJ, et al. Comparison of 2 doses of etanercept (50 vs $100 \mathrm{mg}$ ) in active rheumatoid arthritis: a randomized double blind study. J Rheumatol. 2006;33:659-64.

40. Combe B, Codreanu C, Fiocco U, et al. Etanercept and sulfasalazine, alone and combined, in patients with active rheumatoid arthritis despite receiving sulfasalazine: a double-blind comparison. Ann Rheum Dis. 2006;65:1357-62.

41. Combe B, Codreanu C, Fiocco U, et al. Efficacy, safety and patient-reported outcomes of combination etanercept and sulfasalazine versus etanercept alone in patients with rheumatoid arthritis: a double-blind randomised 2-year study. Ann Rheum Dis. 2009;68:1146-52.

42. Kameda H, Kanbe K, Sato E, et al. Etanercept (ETN) plus methotrexate (MTX) combination therapy resulted in a better radiographic outcome than ETN monotherapy even in patients with active rheumatoid arthritis despite MTX treatment: 104-week results from the JESMR study [abstract]. Arthritis Rheum. 2010;62:1812.

43. Kameda H, Ueki Y, Saito K, et al. Etanercept (ETN) with methotrexate (MTX) is better than ETN monotherapy in patients with active rheumatoid arthritis despite MTX therapy: a randomized trial. Mod Rheumatol. 2010;20:531-8.

44. Klareskog L, van der Heijde D, de Jager JP, et al. Therapeutic effect of the combination of etanercept and methotrexate compared with each treatment alone in patients with rheumatoid arthritis: double- 
blind randomised controlled trial. Lancet. 2004;363:675-81.

45. van der Heijde D, Klareskog L, Rodriguez-Valverde $\mathrm{V}$, et al. Comparison of etanercept and methotrexate, alone and combined, in the treatment of rheumatoid arthritis: two-year clinical and radiographic results from the TEMPO study, a doubleblind, randomized trial. Arthritis Rheum. 2006;54:1063-74.

46. van der Heijde $\mathrm{D}$, Klareskog $\mathrm{L}$, Landewe $\mathrm{R}$, et al. Disease remission and sustained halting of radiographic progression with combination etanercept and methotrexate in patients with rheumatoid arthritis. Arthritis Rheum. 2007;56:3928-39.

47. Moreland LW, Schiff MH, Baumgartner SW, et al. Etanercept therapy in rheumatoid arthritis. A randomized, controlled trial. Ann Intern Med. 1999;130:478-86.

48. Mathias SD, Colwell HH, Miller DP, Moreland LW, Buatti M, Wanke L. Health-related quality of life and functional status of patients with rheumatoid arthritis randomly assigned to receive etanercept or placebo. Clin Ther. 2000;22:128-39.

49. Bathon JM, Martin RW, Fleischmann RM, et al. A comparison of etanercept and methotrexate in patients with early rheumatoid arthritis. N Engl J Med. 2000;343:1586-93.

50. $\mathrm{Hu} \mathrm{D}, \mathrm{Bao} \mathrm{C}, \mathrm{Chen} \mathrm{S}$, et al. A comparison study of a recombinant tumor necrosis factor receptor: Fc fusion protein (rhTNFR:Fc) and methotrexate in treatment of patients with active rheumatoid arthritis in China. Rheumatol Int. 2009;29:297-303.

51. Takeuchi T, Miyasaka N, Zang C, et al. A phase 3 randomized, double-blind, multicenter comparative study evaluating the effect of etanercept versus methotrexate on radiographic outcomes, disease activity, and safety in Japanese subjects with active rheumatoid arthritis. Mod Rheumatol. 2013;23:623-33.

52. Genovese MC, Cohen S, Moreland L, et al. Combination therapy with etanercept and anakinra in the treatment of patients with rheumatoid arthritis who have been treated unsuccessfully with methotrexate. Arthritis Rheum. 2004;50:1412-9.

53. Weinblatt M, Schiff M, Goldman A, et al. Selective costimulation modulation using abatacept in patients with active rheumatoid arthritis while receiving etanercept: a randomised clinical trial. Ann Rheum Dis. 2007;66:228-34.

54. Takeuchi T, Yamanaka H, Harigai M, et al. One-year safety of sirukumab monotherapy: results from a randomized, double-blind, parallel-group, multicenter study in Japanese subjects with moderate to severe rheumatoid arthritis [abstract]. Arthritis Rheumatol. 2015;67:1672.

55. Takeuchi T, Thorne C, Karpouzas G, et al. Efficacy and safety of sirukumab in patients with active rheumatoid arthritis despite disease-modifying anti-rheumatic drug treatment: results of a randomized, double-blind, placebo-controlled study [abstract]. Ann Rheum Dis. 2016;75:717.

56. Aletaha D, Bingham CO 3rd, Tanaka Y, et al. Efficacy and safety of sirukumab in patients with active rheumatoid arthritis refractory to anti-TNF therapy (SIRROUND-T): a randomised, double-blind, placebo-controlled, parallel-group, multinational, phase 3 study. Lancet. 2017;389:1206-17.

57. Burmester GR, Rigby W, van Vollenhoven R, et al. Tocilizumab in combination therapy and monotherapy versus methotrexate in methotrexate-naive patients with early rheumatoid arthritis: clinical and radiographic outcomes from a randomized, placebo-controlled trial [abstract]. Arthritis Rheum. 2013;65:2767.

58. Burmester GR, Rigby W, Ronald F, et al. Tocilizumab combination therapy or monotherapy or methotrexate monotherapy in methotrexate-naive patients with early rheumatoid arthritis: 2-year clinical and radiographic results from a randomized, placebo-controlled trial [abstract]. Arthritis Rheumatol. 2014;66:S811.

59. Burmester GR, Rigby WF, van Vollenhoven RF, et al. Tocilizumab in early progressive rheumatoid arthritis: FUNCTION, a randomised controlled trial. Ann Rheum Dis. 2016;75:1081-91.

60. Burmester G, Pethö-Schramm A, Keane C, Jones G. Tocilizumab monotherapy in early rheumatoid arthritis: data from two phase 3 randomized controlled trials [abstract]. Arthritis Rheumatol. 2015;67:1650.

61. Weinblatt ME, Kremer J, Cush J, et al. Tocilizumab as monotherapy or in combination with nonbiologic disease-modifying antirheumatic drugs: twenty-four-week results of an open-label, clinical practice study. Arthritis Care Res (Hoboken). 2013;65:362-71.

62. Takeuchi T, Kaneko Y, Atsumi T, et al. Adding tocilizumab or switching to tocilizumab monotherapy in RA patients with inadequate response to methotrexate: 24-week results from a randomized controlled study (SURPRISE study) [abstract]. Ann Rheum Dis. 2013;72:62.

63. Dougados M, Kissel K, Sheeran T, et al. Adding tocilizumab or switching to tocilizumab 
monotherapy in methotrexate inadequate responders: 24-week symptomatic and structural results of a 2-year randomised controlled strategy trial in rheumatoid arthritis (ACT-RAY). Ann Rheum Dis. 2013;72:43-50.

64. Herold M, Fasching P, Graninger W, Lunzer R, Zamani O, Leeb B. Efficacy of tocilizumab monotherapy in patients with RA is not influenced by ACPA positivity. Arthritis Rheumatol. 2015;67:499.

65. Pablos JL, Navarro Sarabia F, Blanco FJ, et al. Switch from tocilizumab + methotrexate to tocilizumab monotherapy. Maintenance of response in patients with rheumatoid arthritis at low disease activity [abstract]. Arthritis Rheumatol. 2015;67:S10.

66. Nishimoto N, Yoshizaki K, Miyasaka N, et al. Treatment of rheumatoid arthritis with humanized anti-interleukin- 6 receptor antibody: a multicenter, double-blind, placebo-controlled trial. Arthritis Rheum. 2004;50:1761-9.

67. Ogata A, Tanimura K, Sugimoto T, et al. Phase III study of the efficacy and safety of subcutaneous versus intravenous tocilizumab monotherapy in patients with rheumatoid arthritis. Arthritis Care Res (Hoboken). 2014;66:344-54.

68. Ogata A, Amano $\mathrm{K}$, Dobashi $\mathrm{H}$, et al. Longterm safety and efficacy of subcutaneous tocilizumab monotherapy: results from the 2-year open-label extension of the MUSASHI study. J Rheumatol. 2015;42:799-809.

69. Ogata A, Takagi N, Miwa H. A randomized, doubleblind, parallel-group, phase III study of shortening the dosing interval of subcutaneous tocilizumab monotherapy in RA patients with an inadequate response to subcutaneous tocilizumab every other week [abstract]. Arthritis Rheumatol. 2016;68:1592.

70. Durez P, Depresseux G, Toukap AN, et al. Rate of remission by tocilizumab or methotrexate induction therapy in early active rheumatoid arthritis: results of the Tomera trial. Ann Rheum Dis. 2013;72:623.

71. Jones G. The AMBITION trial: tocilizumab monotherapy for rheumatoid arthritis. Expert Rev Clin Immunol. 2010;6:189-95.

72. Nishimoto N, Hashimoto J, Miyasaka N, et al. Study of active controlled monotherapy used for rheumatoid arthritis, an IL-6 inhibitor (SAMURAI): evidence of clinical and radiographic benefit from an $\mathrm{x}$ ray reader-blinded randomised controlled trial of tocilizumab. Ann Rheum Dis. 2007;66:1162-7.

73. Kawashiri SY, Kawakami A, Yamasaki S, et al. Effects of the anti-interleukin-6 receptor antibody, tocilizumab, on serum lipid levels in patients with rheumatoid arthritis. Rheumatol Int. 2011;31:451-6.

74. Nishimoto N, Miyasaka N, Yamamoto $\mathrm{K}$, et al. Study of active controlled tocilizumab monotherapy for rheumatoid arthritis patients with an inadequate response to methotrexate (SATORI): significant reduction in disease activity and serum vascular endothelial growth factor by IL-6 receptor inhibition therapy. Mod Rheumatol. 2009;19:12-9.

75. Fleischmann R, Kremer J, Cush J, et al. Placebocontrolled trial of tofacitinib monotherapy in rheumatoid arthritis. N Engl J Med. 2012;367:495-507.

76. Strand V, Kremer J, Wallenstein G, et al. Effects of tofacitinib monotherapy on patient-reported outcomes in a randomized phase 3 study of patients with active rheumatoid arthritis and inadequate responses to DMARDs. Arthritis Res Ther. $2015 ; 17: 307$.

77. Tanaka Y, Takeuchi T, Yamanaka H, et al. Tofacitinib (CP-690,550), an oral Janus kinase inhibitor, as monotherapy in Japanese patients with active rheumatoid arthritis: a 12-week phase $2 \mathrm{~b}$ study [abstract]. Arthritis Rheum. 2011;63:2192.

78. Tanaka Y, Takeuchi T, Yamanaka H, Nakamura $H$, Toyoizumi S, Zwillich S. Efficacy and safety of tofacitinib as monotherapy in Japanese patients with active rheumatoid arthritis: a 12-week, randomized, phase 2 study. Mod Rheumatol. 2015;25:514-21.

79. Kremer JM, Bloom BJ, Breedveld FC, et al. The safety and efficacy of a JAK inhibitor in patients with active rheumatoid arthritis: results of a doubleblind, placebo-controlled phase IIa trial of three dosage levels of CP-690,550 versus placebo. Arthritis Rheum. 2009;60:1895-905.

80. Fleischmann R, Strand V, Wilkinson B, Kwok K, Bananis E. Relationship between different clinical measurements and patient-reported outcomes: results from a phase 3 study of tofacitinib or methotrexate in methotrexate-naïve patients with rheumatoid arthritis [abstract]. Arthritis Rheumatol. 2014;66:S1086.

81. Fleischmann R, Strand V, Wilkinson B, Kwok K, Bananis E. Relationship between different clinical measurements and patient-reported outcomes: results from a phase 3 study of tofacitinib or methotrexate in methotrexate-naïve patients with rheumatoid arthritis [abstract]. Ann Rheum Dis. 2015;74:259.

82. Lee EB, Fleischmann RM, Hall S, et al. Radiographic, clinical and functional comparison of tofacitinib 
monotherapy versus methotrexate in methotrexate-naive patients with rheumatoid arthritis [abstract]. Arthritis Rheum. 2012;64:S1049.

83. Fleischmann R, Huizinga TWJ, Kavanaugh A, et al. An analysis of the efficacy of tofacitinib monotherapy in MTX-naïve patients with early RA compared with patients with established RA [abstract]. Arthritis Rheumatol. 2015;67:2741.

84. Fleischmann RM, Huizinga TW, Kavanaugh AF, et al. Efficacy of tofacitinib monotherapy in methotrexate-naive patients with early or established rheumatoid arthritis. RMD Open. 2016;2:e000262.

85. Alten R, Strand V, Fleischmann R, et al. Effects of tofacitinib monotherapy versus methotrexate on patient-reported outcomes in the 2-year phase 3 oral start trial in methotrexate-naive patients with rheumatoid arthritis [abstract]. Ann Rheum Dis. 2014;73:118-9.
86. Strand V, Lee EB, Fleischmann R, et al. Tofacitinib versus methotrexate in rheumatoid arthritis: patient-reported outcomes from the randomised phase III ORAL Start trial. RMD Open. 2016;2:e000308.

87. Strand V, Bergman MJ, Lee EB, et al. Long-term clinical, radiographic and patient-reported outcomes based on RAPID3 responses with tofacitinib at 6 months [abstract]. Arthritis Rheumatol. 2016;68:1648.

88. Charles-Schoeman C, van der Heijde D, Burmester $\mathrm{G}$, et al. Effect of glucocorticoids on clinical and radiographic efficacy outcomes in methotrexatenaive patients with RA receiving tofacitinib or methotrexate monotherapy: analysis of data from a phase 3 trial. Arthritis Rheumatol. 2016;68:2606.

89. Patane $\mathrm{M}$, Ciriaco $\mathrm{M}$, Chimirri $\mathrm{S}$, et al. Interactions among low dose of methotrexate and drugs used in the treatment of rheumatoid arthritis. Adv Pharmacol Sci. 2013;2013:313858. 